OPEN ACCESS

Edited by:

Barbara Zavan,

University of Padova, Italy

Reviewed by:

Hebao Yuan,

University of Michigan, United States

Michael Blank,

Bar-Ilan University, Israe

Marius Sudol,

National University of Singapore,

Singapore

*Correspondence:

Yu-An Chen

d03455002@ntu.edu.tw

Hsin-Fu Chen

hfchen@ntu.edu.tw

Nan-Shan Chang

changns@mail.ncku.edu.tw

Specialty section:

This article was submitted to Molecular and Cellular Oncology,

a section of the journal

Frontiers in Oncology

Received: 31 August 2018

Accepted: 21 January 2019

Published: 11 February 2019

Citation:

Chen Y-A, Lu C-Y, Cheng T-Y, Pan S-H, Chen H-F and Chang N-S (2019) WW Domain-Containing Proteins YAP and TAZ in the Hippo

Pathway as Key Regulators in

Stemness Maintenance, Tissue Homeostasis, and Tumorigenesis.

Front. Oncol. 9:60

doi: 10.3389/fonc.2019.00060

\section{WW Domain-Containing Proteins YAP and TAZ in the Hippo Pathway as Key Regulators in Stemness Maintenance, Tissue Homeostasis, and Tumorigenesis}

\author{
Yu-An Chen ${ }^{1 *}$, Chen-Yu Lu ${ }^{1}$, Tian-You Cheng ${ }^{2}$, Szu-Hua Pan ${ }^{1}$, Hsin-Fu Chen ${ }^{1,3 *}$ and \\ Nan-Shan Chang ${ }^{4,5,6 *}$ \\ ${ }^{1}$ Graduate Institute of Medical Genomics and Proteomics, College of Medicine, National Taiwan University, Taipei, Taiwan, \\ ${ }^{2}$ Department of Optics and Photonics, National Central University, Chungli, Taiwan, ${ }^{3}$ Department of Obstetrics and \\ Gynecology, College of Medicine and the Hospital, National Taiwan University, Taipei, Taiwan, ${ }^{4}$ Institute of Molecular \\ Medicine, College of Medicine, National Cheng Kung University, Tainan, Taiwan, ${ }^{5}$ Department of Neurochemistry, New York \\ State Institute for Basic Research in Developmental Disabilities, New York, NY, United States, ${ }^{6}$ Graduate Institute of \\ Biomedical Sciences, College of Medicine, China Medical University, Taichung, Taiwan
}

The Hippo pathway is a conserved signaling pathway originally defined in Drosophila melanogaster two decades ago. Deregulation of the Hippo pathway leads to significant overgrowth in phenotypes and ultimately initiation of tumorigenesis in various tissues. The major WW domain proteins in the Hippo pathway are YAP and TAZ, which regulate embryonic development, organ growth, tissue regeneration, stem cell pluripotency, and tumorigenesis. Recent reports reveal the novel roles of YAP/TAZ in establishing the precise balance of stem cell niches, promoting the production of induced pluripotent stem cells (iPSCs), and provoking signals for regeneration and cancer initiation. Activation of YAP/TAZ, for example, results in the expansion of progenitor cells, which promotes regeneration after tissue damage. YAP is highly expressed in self-renewing pluripotent stem cells. Overexpression of YAP halts stem cell differentiation and yet maintains the inherent stem cell properties. A success in reprograming iPSCs by the transfection of cells with Oct3/4, Sox2, and Yap expression constructs has recently been shown. In this review, we update the current knowledge and the latest progress in the WW domain proteins of the Hippo pathway in relevance to stem cell biology, and provide a thorough understanding in the tissue homeostasis and identification of potential targets to block tumor development. We also provide the regulatory role of tumor suppressor WWOX in the upstream of TGF- $\beta$, Hyal-2, and Wnt signaling that cross talks with the Hippo pathway.

Keywords: Hippo pathway, WW domain proteins, tissue homeostasis, regeneration, stem cell, induced pluripotent stem cells, tumorigenesis 


\section{INTRODUCTION}

The Hippo pathway was originally identified by genetic screens of tumor suppressors for tissue growth control in Drosophila melanogaster. Recent advances in the identification of the mammalian Hippo pathway components and functional implications highlight the role of the pathway in organ development, tissue regeneration, stem cell maintenance, and tumorigenesis (1-4). The pathway is evolutionarily conserved.

The stem cell has indeed generated a great interest for scientists in the past decades and attracted more and more attention from the public recently. The unique properties of stem cells give substantial clues for clinical doctors, biologists, and scientists to solve problems in fundamental biology during the developmental process and the aberrant progression of degenerative diseases and cancer. Despite extensive investigations into the underlying mechanisms of stemness properties, what has not been known is the key signaling pathway, which orchestrates the network for conferring stemness maintenance and tissue homeostasis. Exploration of the Hippo pathway on stem cell biology has shed light on the developmental path (5-8). Here, we focus on discussing how the key WW domain-containing YAP and TAZ of the Hippo pathway contribute their regulatory role via the $\mathrm{WW}$ domain and $\mathrm{PY}$ (proline-tyrosine) motif interactions.

\section{THE HIPPO PATHWAY}

The Hippo pathway took the name from aberrant tissue overgrowth and neoplasia that generates a unique "hippopotamus"-like phenotype. Beginning in 1995, two studies first discovered the Warts (Wts) gene deletion, which caused robust multiple tissue overgrowth in $D$. melanogaster $(9,10)$. Later, researchers uncovered more components within this pathway, including scaffolding protein Salvador (Sav) (11), Ste20-like kinase Hippo (Hpo) (12-14), and Mob as tumor suppressor (Mats) (15). These mutant proteins may cause tissue overgrowth in Drosophila. Soon after the discovery of the Salvador/Warts/Hippo pathway, Yorkie (Yki) was shown to be one of the key functional effectors of this pathway from the screening of Wts-interacting proteins (16). The Hippo pathway-regulated overgrowth in organs has quickly attracted broad attention and led to the development of transgenic mouse models $(16,17)$.

\footnotetext{
Abbreviations: YAP, Yes-associated protein; TAZ, Transcriptional co-activator with PDZ binding motif; iPSCs, Induced pluripotent stem cells; Oct3/4, Octamerbinding transcription factor 4; Sox2, SRY (sex determining region Y)-box 2; PY motif, Proline-tyrosine motif; MST1/2, Mammalian sterile 20-like 1/2; SAV1, Salvador; LATS1/2, Large tumor suppressor homolog 1/2; MOB1A/B, MOB kinase activator 1A/B; TEAD, Transcriptional enhancer factor domain; VGLL4, Vestigiallike family member 4; NF2, Neurofibromin 2/ Merlin; MAP4Ks, Mitogen-activated protein kinase kinase kinase kinase; PRM, Proline-rich peptide motifs; TB, TEADbinding region; PPXY, Proline/proline/any amino acid/tyrosine; PP2A, Protein Phosphatase 2A; Tgi, Tondu-domain-containing growth inhibitor; VGLL4, Vestigial-like family member 4; CTGF, Connective tissue growth factor; Cyr61, Cysteine-rich 61; TE, Trophectoderm; ICM, Inner cell mass; AMOT, Angiomotin; ESCs, Embryonic stem cells; BMP, Bone Morphogenetic Protein; TICs, Tumor initiating cells.
}

\section{Core Components of Hippo Pathway}

The Hippo pathway is essentially a cascade of kinases, comprising transcription coactivators and DNA-binding proteins. Although the pathway was first discovered in Drosophila, it is evolutionarily conserved in mammals. The mammalian orthologs of Hpo, Sav, Wts, Mats, and Yki are Mammalian sterile 20-like 1/2 (MST1/2, also named as STK4/3), Salvador (SAV1), Large tumor suppressor homolog 1/2 (LATS1/2), MOB kinase activator 1A/B $(\mathrm{MOB} 1 \mathrm{~A} / \mathrm{B})$, and Yes-associated protein (YAP)/Transcriptional co-activator with PDZ binding motif (TAZ), respectively (Figure 1 and Table 1) $(15,18-21,29)$. The best-known role of the Hippo pathway is to orchestrate organ development and control tissue homeostasis through modulation of cell proliferation, apoptosis, migration, and differentiation $(7,8)$. Hippo pathway also regulates stem cell self-renewal and expansion and tissue regeneration (30-32).

\section{Numerous Initiating Signals for the Responsive Kinase Cascade: An Integrated Action or a Conundrum in Chaos?}

The Hippo pathway receives a broad range of signals, including extracellular mechanical force, hormonal cues, and intrinsic cell physical mechanism, so as to control cell polarity and cytoskeletal organization, and interactions with proteins in the extracellular matrix (33-35). Numerous proteins participate in the initiation of the Hippo signaling. For example, protein kinases, including Src kinase, protein kinase A (PKA), PAR-1/MARK kinase, and TAO kinase are involved $(1,36)$. Extracellular soluble factor Amphiregulin (37), matrix Agrin proteoglycan and Integrins (38), and cell junctional proteins Echinoid and CadherinCatenin complex $(39,40)$ participate in the signaling network. Furthermore, cell polarity proteins Crumbs, and Scribble complexes (41, 42), G-protein-coupled receptor (GPCR) and Wnt/beta-catenin signal pathways (43,44), and cytoskeletal Spectrin, Myosin II, and F-actin (45-49) are integrated in the signaling network (Figure 2). Among these signals, many of them collaborate with each other, whereas others may be in conflict. How each cell selectively sorts out which signal(s) to respond and/or converge all signals, or ignore and terminate them, remains to be a critical issue to resolve.

When cells receive the extracellular upstream activation signals, the signal receiver MST1/2 (or Drosophila Hpo) phosphorylates LATS1/2 (or Drosophila Wts) and MOB1 (or Drosophila Mats) in a canonical manner, with the assistance of cofactor SAV1 (or Drosophila Sav). SAV1 is a WW domain-containing protein needed for integrating the upstream signal(s). Then, the activated LATS1/2, in turn, triggers the phosphorylation of the major coactivators YAP/TAZ (two homologs of Drosophila Yki) at multiple residues (Figure 1). Phosphorylation of YAP at S127 (corresponding to S89 on TAZ) promotes its binding with 14-3-3, thus resulting in the cytoplasmic retention (20). Phosphorylation of YAP/TAZ at S381 and S311, respectively, creates a binding site for casein kinase 1 (CK1) and subsequent phosphorylation by CK1 $\delta / \varepsilon$ at the DSGxS motif. Then SCF $\beta T r C P$, a multi-subunit SKP-CULLIN-F-box (SCF) ligase complex specifically recognizes the phosphodegron 


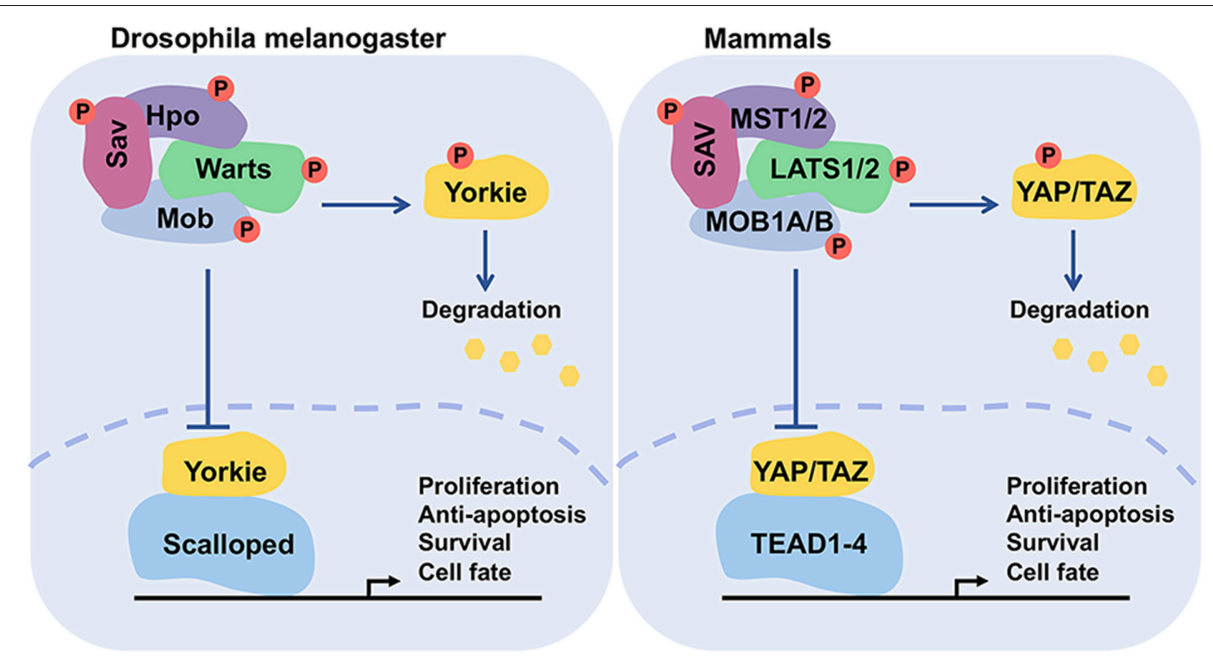

FIGURE 1 | Functional conservation of the core components of Hippo pathway. The functionally conserved factors of Drosophila melanogaster and mammals are matched by color. This network controls the transcriptional events for regulating cell proliferation, survival, and death.

TABLE 1 | Hippo pathway components and major functions.

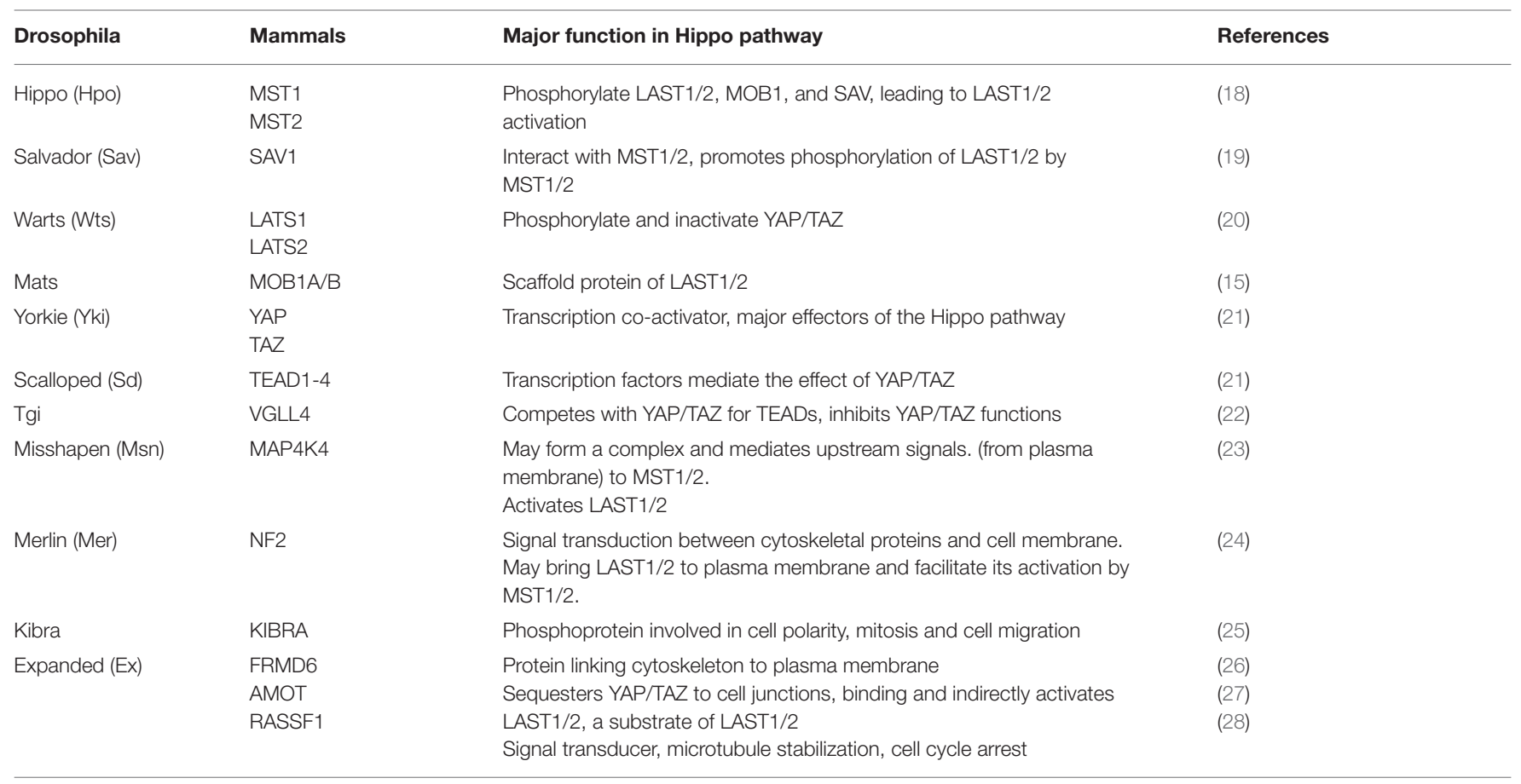

DpSGxpS of YAP and TAZ for leading to eventual YAP/TAZ ubiquitination and degradation $(20,50,51)$. YAP protein is also degraded via autophagy (52). Unphosphorylated YAP/TAZ complex translocates to the nucleus to drive transcriptional activation (Figure 2). The phosphorylation/degradation strategy has been seen in many biological molecules for their turnover. For example, tumor suppressor p53 is subjected to Mdm2mediated degradation in the cytoplasm, whereas phosphorylated p53 is stabilized in the nucleus.
MST1/2 in Hippo pathway can be activated without upstream kinases. The phosphorylation cascade is enhanced by MST1/2 dimerization (53). Active MST1/2 phosphorylates SAV1 and MOB1A/B (19, 29), which assists MST1/2 to recruit and phosphorylate LATS1/2 at their hydrophobic motifs (T1079 for LATS1 and T1041 for LATS2) (24, 54). Another key component in this action is NF2 (or Merlin), which directly interacts with LAST1/2 and promotes their phosphorylation (24). LATS1/2 subsequently undergoes autophosphorylation (18), and 


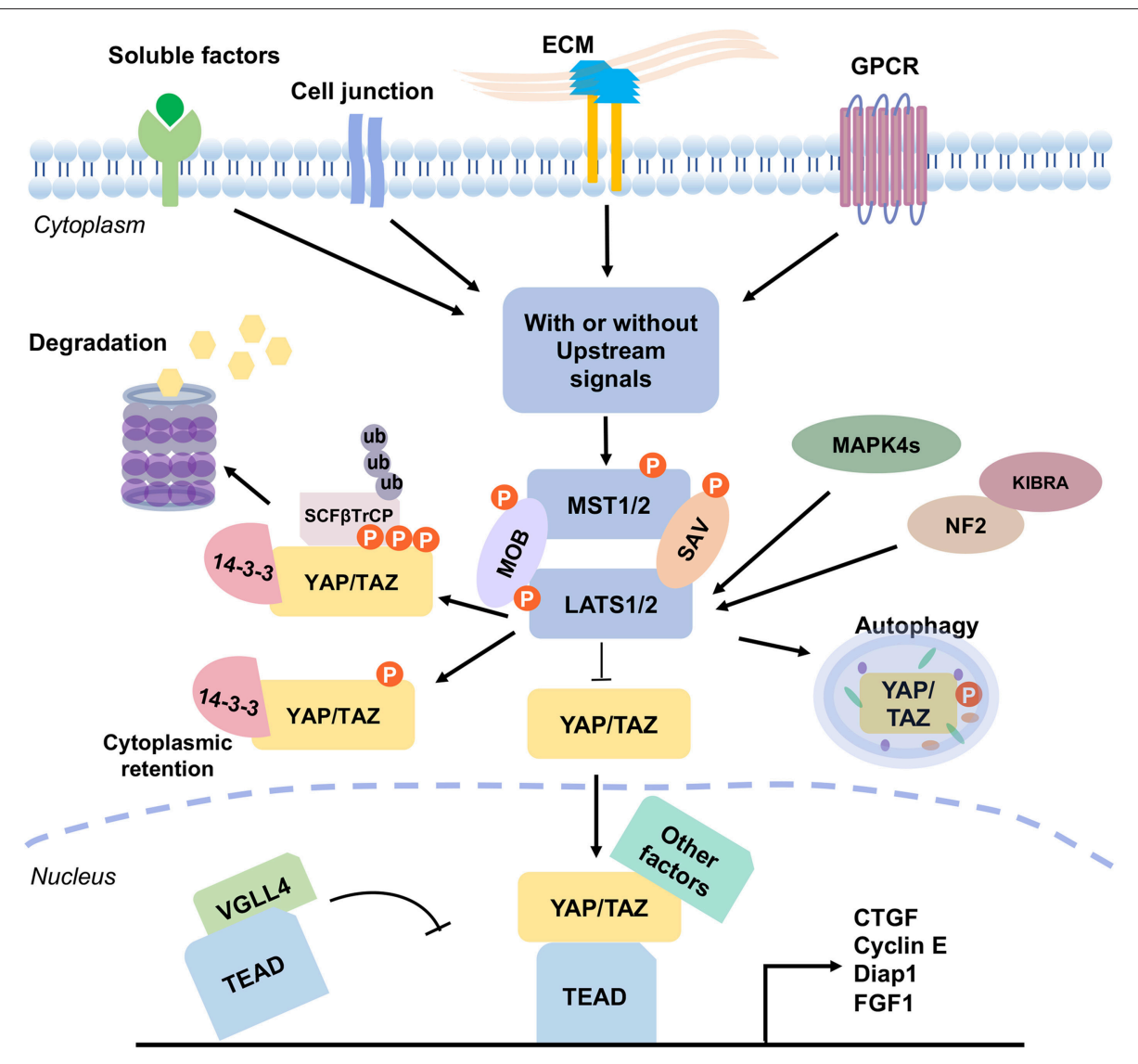

FIGURE 2 | The mammalian Hippo pathway signaling. Various signal stimulators activate the Hippo pathway, which includes GPCR, cell junction and ECM proteins, and soluble factors. These signals regulate the phosphorylation of MST1/2 and LATS1/2 kinases to further induce YAP/TAZ activation. Without the upstream signals, KIBRA interacts with NF2 to promote the pathway activity. Also, NF2 and MAPK4s directly interact with LAST1/2 and promote LATS1/2 phosphorylation (pLATS1/2). Then, pLATS1/2 phosphorylates YAP/TAZ. And, the phosphorylated YAP/TAZ presents a 14-3-3 biding site and SCF $\beta$ TrCP specific recognition site, which causes cytoplasmic retention of YAP/TAZ and results in YAP/TAZ degradation. YAP protein is also degraded via autophagy. VGLL4 acts as a transcriptional repressor by competing with YAP/TAZ for binding TEADs. Unphosphorylated YAP/TAZ complex translocates into the nucleus, and acts as transcription coactivators by forming complexes with various transcriptional factors, such as TEADs. Binding of YAP/TAZ with TEAD prevents VGLL4 from associating with the complex, and consequently drives the expression of numerous genes which are related to cell proliferation, survival, and migration. The signaling outcome includes induction of cell cycle regulator cyclin E, cell-death inhibitor Diap1, connective tissue growth factor (CTGF), and fibroblast growth factor (FGF1), and etc.

triggers the phosphorylation of YAP and TAZ for functional inactivation (55). Moreover, in parallel to MST1/2, two groups of MAP4Ks (mitogen-activated protein kinase kinase kinase kinase), MAP4K1/2/3/5 [homologs of Drosophila happyhour (Hppy)] and MAP4K4/6/7 [homologs of Drosophila misshapen (Msn)] directly phosphorylate LATS1/2 at their hydrophobic motifs and result in LATS1/2 activation, which consequently inactivates $\operatorname{YAP} / \mathrm{TAZ}(23,56,57)$.

Overall, like many signaling pathways, the Hippo phosphorylation cascade is well-orchestrated and evolutionarily conserved. However, the ultimate outcome can be altered, either enhanced, or altered, by various signal stimulators. Conceivably, a single stimulator Wnt or growth factor, for example, may activate not only the Hippo pathway but also other molecular paths, thereby either toning down or escalating the outcomes. Nonetheless, there are multiple signal initiators for the Hippo pathway. The signal flow could be in either a concerted manner or ends up in chaos.

Among all the factors, how can those signals possibly work in a concert or contradictory manner? In short, GPCR either activates or inhibits the Hippo-YAP pathway depending on the signaling effected by the soluble Serumborne lysophosphatidic acid and sphingosine 1-phosphophate (44). Soluble factor Amphiregulin binds EGFR and acts as an autocrine growth factor for establishing a positive autocrine regulatory feedback loop between EGFR and YAP1, which is important in cancer progression (37). Cell junction proteins Echinoid and E-cadherin inhibit YAP/TAZ activation. Echinoid physically binds and stabilizes the Hpo-binding partner Sav at adherens junctions. Loss of Echinoid compromises Yki phosphorylation, resulting in elevated Yki activity that increases Hpo-targeted gene expression and drives tissue overgrowth (39). Also, E-cadherin inhibits YAP/TAZ activation 
without involving the upstream signals of the Hippo pathway. This is achieved via the regulation of alpha/beta-catenin pathway (40).

\section{YAP AND TAZ ARE WW DOMAIN-CONTAINING PROTEINS}

The WW domain is a structural module that mediates proteinprotein interactions through recognition of proline-rich peptide motifs (PRM) and phosphorylated serine/threonine-proline sites (58). WW domains are found in at least 52 different structural and signaling proteins in the human proteome. They participate in a variety of cellular processes and have been implicated in major human diseases such as cancer and neurodegeneration. In the Hippo pathway, SAV, KIBRA, YAP, and TAZ are the critical WW domain-containing proteins (59-61). While WW domains are responsible for protein/protein binding, the actual functional areas in the WW domain-containing proteins may not necessarily be on the WW domain areas. Phosphorylation in particular amino acid residues outside of the WW domain(s) may confer crucial molecular functions both in vivo and in vitro.

\section{The Configurations and Binding Motifs of YAP/TAZ}

The human YAP gene is located on chromosome11q22. YAP protein was first identified as a proline-rich phosphoprotein, and is capable of binding the $\mathrm{SH} 3$ domain of Yes and Src protein tyrosine kinases (62). YAP mRNA is not only ubiquitously expressed in a broad range of tissues, but also is expressed during the entire developmental process (63). The human TAZ gene is mapped at chromosome 3q23-q24, and encodes TAZ protein (also known as WW-domain containing transcriptional regulator 1 , WWTR1). Similarly, the TAZ gene is expressed in various tissues and amplified in many cancer cells (64).

Structurally, YAP and TAZ proteins share nearly half of the protein sequence identity and have a very similar topology. YAP protein has 488 amino acids, possessing a TEAD-binding region (TB), one or two WW domains in the isoforms, an SH3-binding motif, a coiled-coil domain, a transcription activation domain, an $N$-terminal proline-rich domain, and a $C$-terminal PDZ-binding motif. The WW domain has two-conserved tryptophan (W) residues separated by 20-23 amino acids. TAZ protein consists of 400 amino acids and has a similar domain organization with YAP, although it lacks the second WW domain, the SH3-binding motif, and the proline-rich domain (Figure 3).

The WW domains of YAP and TAZ physically interact with the "PPXY motifs (proline/proline/any amino acid/tyrosine)" in many proteins, including transcriptional factors (65). The TEAD-binding domain (TB) of YAP and TAZ recognizes the transcriptional enhancer factor domain family (TEAD) family of transcription factors and activates target gene expression, whereas the 14-3-3 binding motif is involved in the degradation of YAP and TAZ. As mentioned previously, in a canonical pathway, LATS phosphorylates YAP/TAZ and promotes the binding of 14-3-3 with YAP/TAZ. 14-3-3 binds YAP/TAZ via the phosphorylation sites S127 of YAP and S89 of TAZ, which results in cytoplasmic retention of YAP/TAZ. Certain upstream regulators, such as $\alpha$-catenin, require the binding of 14-3-3 with the YAP pS127 site for subsequent inhibition of cell proliferation (66). Protein Phosphatase 2A (PP2A) dephosphorylates the 143-3 docking site on YAP, resulting in the nuclear import of YAP. The PDZ-binding motif is required for binding with another PDZ domain, and this can be found in many transmembrane or cytoskeleton-associated proteins. The PDZ-binding domains display to direct the cellular distribution of YAP and TAZ $(67,68)$. Functionally, YAP and TAZ are transcriptional co-activator and work synergistically with transcription factor companions such as TEAD and RUNX1/2, SMAD family members (69-71).

\section{YAP/TAZ Action in Downstream Gene Targets}

YAP and TAZ cannot physically bind chromosomal DNA and thus act as co-activators with DNA-binding transcription factors to regulate a large number of target genes (72-75). Both proteins regulate the gene expression mainly by binding TEAD14 [homologs of Drosophila Scalloped (Sd)] (21). The interaction between YAP/TAZ and TEAD drives the expression of numerous genes for cell proliferation, survival, and migration. The gene products are the cell cycle regulator cyclin E, cell-death inhibitor Diap1, connective tissue growth factor (CTGF), cysteine-rich 61 (Cyr61), fibroblast growth factor (FGF1), and bantam microRNA $(37,69)$. Mouse models harboring the deletion of Mst1/2, Sav1, Mob1A/B, NF2, or Last1/2, or Yap overexpression, exhibit upregulated Tead target gene expression, and increased expansion of progenitor cells and tissue overgrowth (76-79). thereby manifesting the importance of these genes in the Hippo pathway (Figure 2).

Importantly, Tondu-domain-containing growth inhibitor (Tgi) and Vestigial-like family member 4 (VGLL4, an ortholog of Tgi) are well known regulators of Yki and YAP/TAZ, respectively. Tgi directly competes with Yki for Sd binding in nucleus, restrains the Yki-regulated transcription $(22,69)$. When Hippo signaling cascade is on, Tgi and Sd form a complex to exert transcriptional repression. Conversely, when Hippo signaling is off, Yki translocates into the nucleus and takes the place of Tgi from Sd, permitting the expression of Yki target genes (69). By the same token, in mammals, VGLL4 competes with YAP/TAZ for TEAD binding $(80,81)$.

The YAP/TAZ complex also regulates the expression of certain genes via binding specific factors. For instance, the YAP/TAZ complex interacts with the nucleosome remodeling and histone deacetylase (NuRD) complex, and decreases the transcription of target genes (82). Moreover, YAP is identified as a regulator for miRNA biogenesis by modulating miRNA 'processing enzymes microprocessor or Dicer complex $(83,84)$. Further, YAP directly induces the production of miR-130a, which represses VGLL4 expression, and forms a positive feedback loop for promoting the amplification of YAP activity (85). Hence, the observations suggest that YAP/TAZ regulate gene transcription through coordination of multiple mechanisms (86). 

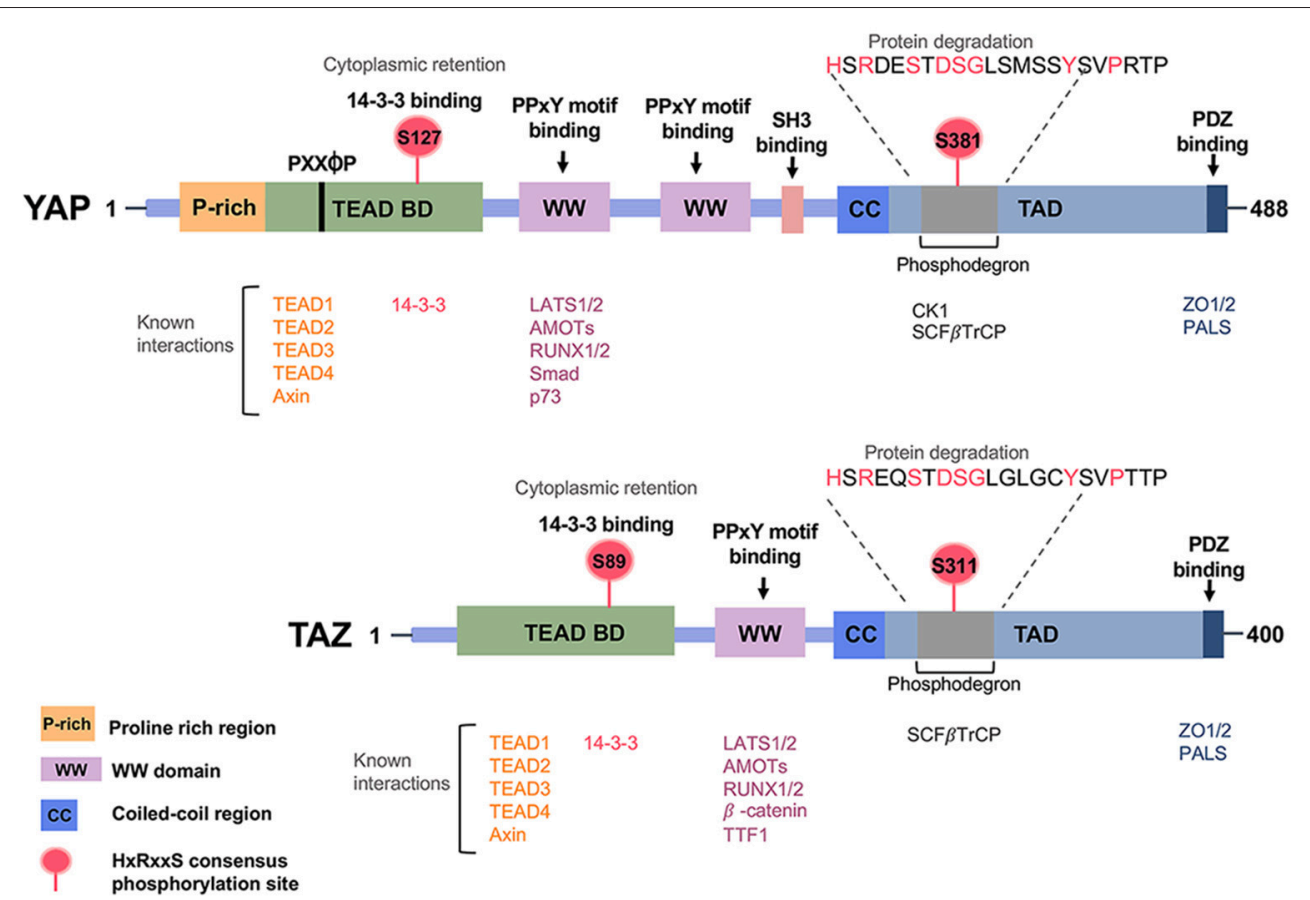

FIGURE 3 | Regulatory domains of the Hippo pathway effector proteins YAP/TAZ. Prominent regions include the WW domain(s), the coiled-coil (CC) domain, the SH3-binding domain, the TEAD transcription factor-binding domain, the transcriptional activation domain (TAD) and the PDZ-binding motif.

\section{HIPPO SIGNALING IN ORGAN SIZE CONTROL AND TISSUE HOMEOSTASIS}

The remarkable effect on organ size and tissue homeostasis regulation is the best-known feature of the Hippo pathway. How the Hippo pathway senses the physiological cues to modulate organ size is largely unknown. It is generally believed that the mechanical force or tension may determine the tissue growth and restrain YAP/TAZ activation when the organ reaches its proper size. Organ sizes are restricted/induced by some soluble factors via the autocrine/paracrine mechanism in a concentrationdependent manner (87). Still, a crucial point is that how the cells on the outer surface of an organ sense the overgrowth from the inner mass of the organ, and vice versa. Does the Hippo pathway coordinate the even cell growth, cell shape, and spatial relationship of all cells in an expanding organ?

\section{Effects of Hippo Signaling on Organ Size Regulation}

In Drosophila, dysregulation of the Hippo pathway kinases (Hpo and Wts) or upstream regulators (Ex, Mer, Kibra, Ft, etc.) promotes Yki-induced cell proliferation and finally leads to tissue/organs overgrowth $(16,25,26,28)$. Under physiologic conditions, the liver returns to its normal size while Yap expression is restored at the background level (88). The longterm persistent Yap activation causes the onset of hepatocellular carcinoma (30). Liver conditional knockout of Mst1/2, Sav1, or Nf2 causes liver enlargement $(76,89)$. Moreover, deletion of Sav1, Mst1/2, or Lats1/2 gene brings upon embryonic heart enlargement.
The genetic manipulation of Yap robustly affects the proliferation and survival of cardiomyocytes (90-92). Substantial evidence revealed that tissue-specific deletion of Yap gives rises to abnormalities in several organs, including heart, skin, and kidney (93-95). Abnormal activation of YAP/TAZ makes aberrant influences in multiple organs, such as liver, heart, stomach, and spleen. However, tissue-specific deletion of Yap does not cause defects in the breast and intestine $(78,96)$. Mammary glands and intestine remain relatively normal upon Yap deletion (96-98). These findings imply that differential regulation of the Hippo pathway is utilized for size regulation among organs. Despite the outstanding findings, the mechanical force from within or outside the organ to balance the cellular size, shape, and tension, along with regulation by the Hippo pathway and/or others, is not well-defined.

\section{Hippo Signaling Regulation in Tissue Regeneration}

For adult organisms, damage, and impair can barely be avoided during the lifetime. Thus, tissue regeneration is especially important. The Hippo signaling pathway, especially Yap, participates in organ regeneration. For example, liver regenerates efficiently post damage (e.g., partial hepatectomy), due to the proliferation of hepatocytes to restore liver mass. The transcriptional activity of Yap/Tead is increased during liver regeneration, meanwhile Mst $1 / 2$ and Lats $1 / 2$ are down-regulated toward the completion of tissue repair. When the regeneration is finished, the Yap activity is repressed and Mst1/2 and Lats1/2 inhibition is released automatically $(89,99-101)$. 
Similarly, the study in the mouse model showed that intestines can effectively repair and regenerate from colitis induced by dextran sulfate sodium (DSS). However, the regenerative capability is severely obstructed upon tissue-specific knockout of Yap (96). Marvelously, overexpression of Yap restores some myocardial regenerative capability, although the regeneration of the adult heart is very limited. In contrast, specific deletion of Yap obstructs the regeneration of the neonatal heart (91, 92, 102). Again, the studies imply that organ formation and morphogenesis is not only just the proper function of YAP but also other cellular factors are involved.

\section{YAP/TAZ in Progenitor Cell}

Progenitor cells play an important role in tissue homeostasis and regeneration. A high YAP/TAZ activity has been observed in the stem cells or progenitor cells of multiple tissues. Activation of YAP, which usually leads to the expansion of progenitor cells, impairs cell differentiation of target tissues such as intestine, liver, skin, and nervous system (96, 97, 103, 104). In intestinal crypts, YAP is highly localized in the nucleus promoting target gene expression in basal progenitor cells and in intestinal stem cells $(30,96,105)$. In chick embryo, YAP and its transcriptional targets CTGF and CYR61, which are known to stimulate cell proliferation, are abundant during early development of the stomach (106). Moreover, YAP is highly expressed in the nuclei of single-layered basal epidermal progenitors. YAP is crucial in promoting the expansion of basal epidermal progenitors, proliferation, and inhibition of terminal differentiation through transcriptional target Cyr61. After initiation of hair follicle morphogenesis, YAP translocates to the cytoplasm of differentiating cells (107). Taken together, the capability of YAP/TAZ on cell proliferation and progenitor cell expansion suggests its decisive role in organ development, tissue homeostasis, and injury-induced regeneration. As a negative control mechanism, YAP/TAZ has to be under proper phosphorylation in order to be subject to degradation by the 14-3-3/SCF $\beta \operatorname{TrCP} /$ ubiquitin/proteasome system.

\section{HIPPO PATHWAY IN EARLY EMBRYONIC DEVELOPMENT, STEMNESS MAINTENANCE AND PROMOTING THE PRODUCTION OF INDUCED PLURIPOTENT STEM CELLS (iPSCs)}

Stem cells possess the unique properties of self-renewal and differentiation potency, which undergo asymmetric replication to divide one daughter cell identically to the parental cell and another daughter cell differentiating into destined cell type (108). In mammals, there are two major types of stem cells: pluripotent stem cells and somatic stem cells (109). Pluripotent stem cells, such as embryonic stem cells (ESCs), which are isolated from the inner cell mass (ICM) of blastocysts during development. These cells are capable of differentiating into near all cell types of three germ layers-ectoderm, endoderm, and mesoderm. Somatic stem cells are isolated in various adult tissues. The somatic stem cells and progenitor cells function in the repair system in different adult tissues and maintain tissue growth, homeostasis and regeneration through expanding cell numbers and replacing old or injured cells. Stem cells play critical roles in both embryonic developmental and adult stages. Therefore, it is important to understand the molecular mechanisms underlying the stemness maintenance. Appropriate tools are needed to pry into the perfect prospectus regarding how one single cell grows into a multicellular organism under a concerted and yet a regulatory signaling network.

\section{YAP/TAZ in TE and ICM Specification}

Stem cells possess the drive to proliferate, differentiate, and migrate during development and tissue regeneration, in which the Hippo pathway is involved. The first cell lineage specification during embryonic development is a special feature of mammalian development with the emergence of the inner cell mass (ICM) and trophectoderm (TE).

In mice, after the gametes are fertilized in the oviduct, the embryo divides into an eight-cell morula with a relatively slow dividing rate. Each cell of the morula is called a blastomere. During the preimplantation stage, the blastomeres form adherens and tight junctions, and acquire apical-basal polarity, as well as an increase in the surface contact with its neighbors in a process called compaction (110). This creates the polarization of the cells within the morula. As these cells divide into the 16-cell stage, the innermost and more compacted cells lose their polarity. The differences between the inner and the outer cells bring about a disparate distribution of TAZ/YAP proteins, followed by further division to yield a blastocyst composed of about 32 cells. By entering the blastocyst stage, the subcellular localization of TAZ/YAP determines the first cell fate choice in the embryo-the settlement of embryonic cells to become either TE or ICM. For TE cells, TAZ/YAP is accumulated in the nuclei but distributed all over the cytoplasm of the ICM cells (111). The TE cells at the outer layer of the blastocyst form extraembryonic tissues, whereas ICM gives rise to the definitive structures of the fetus (112) (Figure 4).

\section{YAP/TAZ in Embryonic Development}

Yap knockout mouse exhibits arrest in the division in the blastomere before entering the morula stage (16-32 cells) and embryonic lethal at E8.5 with a vascular defect of yolk sac $(63,111,113-115)$. Similarly, deletion of both Yap and Taz results in cell fate specification defects, leading to embryo death at the morula stage prior to the specification of TE or ICM $(87,111)$, again suggesting the Hippo pathway and YAP/TAZ play vital roles at early embryonic development.

When the Hippo signaling pathway is inactive, YAP promotes trophectoderm fates in the embryo. However, when the Hippo signaling is activated, YAP relocates from the cell nucleus to the cytoplasm to promote pluripotent cell fates $(116,117)$. The differential distributions of YAP/TAZ in the TE and ICM causes distinct gene expression signatures, where the nuclear TAZ/YAP complex directs a TE-specific transcriptional program by interacting with TEAD transcription factors. For example, at the blastocyst stage, YAP/TAZ induces $C d x 2$ and Gata3 transcription by modulating the activity of TEAD in the outer TE cells $(111,118)$. High YAP activity is necessary for TE 


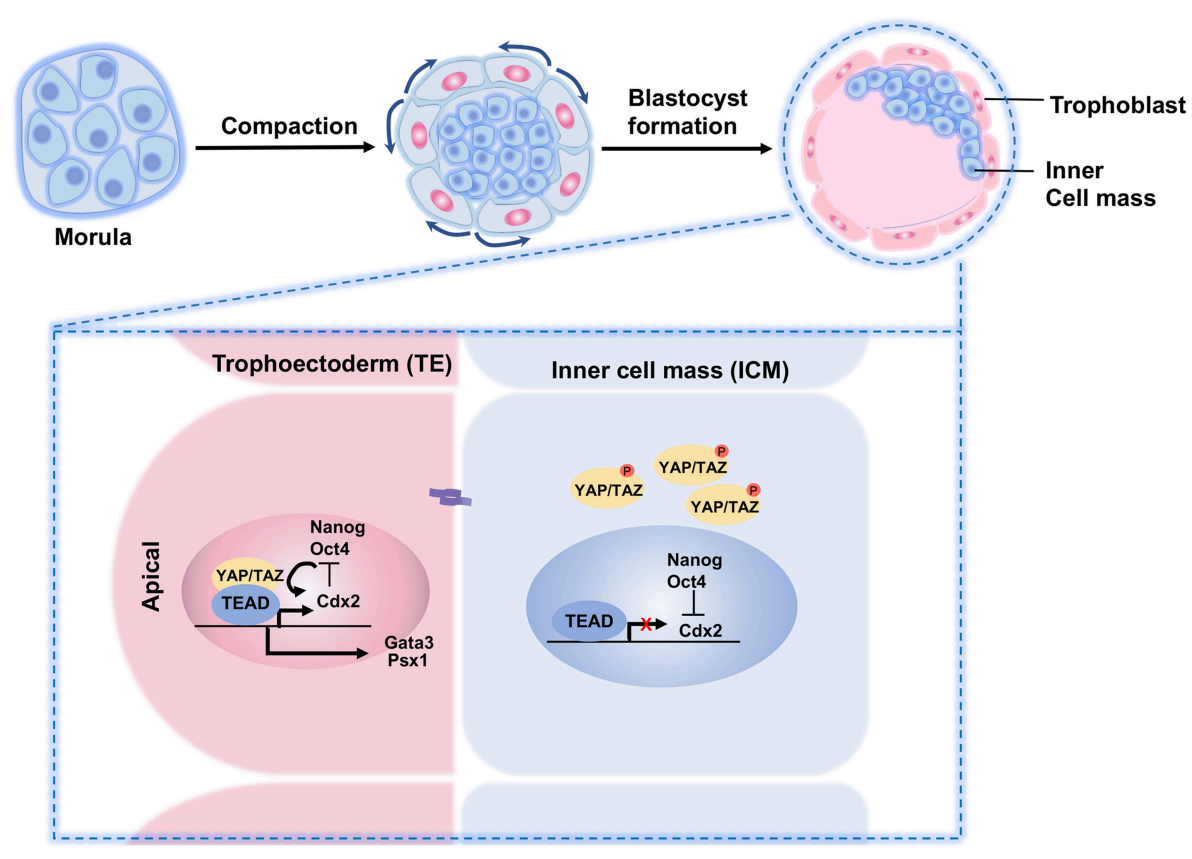

FIGURE 4 | A schematic illustration of YAP/TAZ regulation of TE and ICM specification in preimplantation embryo. During preimplantation, the outer blastomeres of the embryo form an outer epithelial trophoectoderm (TE) that envelopes the remaining blastomere and the inner cell mass (ICM). The Hippo pathway plays a crucial role in the cell fate determination. In the outer cells, nuclear YAP and TEAD4 regulate specification of the TE lineage through activation of the TE-specific genes such as Cdx2 and Gata3. In the inner cells, cell-cell adhesions influence the Hippo signaling. Activated Hippo pathway impairs YAP nuclear localization in the ICM lineage, thereby limiting TEAD4 transcription and abrogating the expression of outer TE-specific genes.

specification. For example, in Tead4 ${ }^{-/-}$embryos, all blastomeres are specified to the ICM lineage (119-121).

\section{TEADs}

TEADs are the earliest genes highly expressed during embryo development, and are the transcription factors with YAP/TAZ as cofactors. Among them, TEAD4 is required for specification of the TE lineage during preimplantation in mammals. TEAD4 activity depends on the nuclear localization of YAP, which is regulated by cell-cell contacts and LATS1/2-mediated phosphorylation for negative regulation. Phosphorylated YAP undergoes degradation in the cytoplasm. Increased nuclear localization of TAZ/YAP, resulting from the deletion of Lats1/Lats2, leads to amplified $C d x 2$ expression, which prevents proper specification of the ICM (111). In addition, the junctionassociated angiomotin (AMOT) family proteins angiomotin (Amot) and angiomotin-like 2 (Amotl2) are essential for Hippo pathway activation and appropriate cell fate specification (27). Depleting LATS1/2, NF2, or AMOT/AMOTL2 turns all cells into TE, and these embryos fail to establish ICM-derived tissues (119-121). In contrast, knockout of TEAD leads to the loss of $C d x 2$ expression and prohibits the embryos to form the TE with a consequence of all cells transforming into ICM $(24,122)$.

Depletion of both Mob1a and Mob1b, which are regulators of LATS1/2 activity, also results in developmental defects, with embryo arrest at E6.5 prior to gastrulation (110). Analysis of $M O B 1 A / B$-deficient blastocysts revealed aberrant nuclear YAP localization and modest growth failure of ICM, with few defects associated with the TE. Similar to the Lats1/2-deficient embryos, depletion of both Amot and Amotl2 also increases nuclear YAP localization and $C d x 2$ expression throughout both inner and outer cell populations, thereby resulting in severe preimplantation defects. However, depletion of either Amot or Amotl2 alone did not cause pre-implantation defects, indicating redundancy between AMOT family members (117).

Additionally, Neurofibromin 2 (NF2) (or Merlin) and AMOT, two upstream components of the Hippo pathway, facilitate YAP phosphorylation via LATS1/2 during cell fate specification of mouse preimplantation development. Mechanistic studies have revealed that LATS1/2 induces the phosphorylation of AMOT in the inner cells of the pre-implantation embryo, promoting its association with NF2 at cell membranes, and consequently amplifying the TAZ/YAP phosphorylation (117). Altogether, these results demonstrate a critical role for YAP and Hippo signaling cascade in the process of cell fate specification and development in early embryos.

\section{TAZ/YAP in Stem Cell Pluripotency}

The Hippo pathway regulates pluripotent stem cells in vitro. TAZ/YAP participates in the differentiation of embryonic stem cells (ESCs) derived from the ICM of the blastocyst. ESCs are pluripotent stem cells capable of self-renew and differentiating into near all functional cell types in an adult organism. YAP is highly expressed in self-renewing ESCs. Downregulation of YAP protein and mRNA levels correlates 
with significantly decreased pluripotent markers along the line of ESC differentiation. In addition, YAP is sequestered and thereby inactivated in the cytoplasm during ESC differentiation, and consequently a large number of major genes for stem cell maintenance and function, including Nanog, Oct3/4, and Sox2, are repressed. Overexpression of Yap inhibits ESC differentiation and maintains stem cell properties even under differentiation culture conditions, while knockdown of Yap/Taz is sufficient to result in the impairment of ESC phenotype (123126). Furthermore, restricting YAP and TEAD2 expression or inhibiting TEAD function induces differentiation toward the endoderm lineage. In contrast, deletion of $M s t 1 / 2$ in ESCs induces cell proliferation and breaks the process of differentiation (127). Further, bone morphogenetic protein (BMP) and leukemia inhibitory factor (LIF) signals maintain mouse ESCs in an undifferentiated and pluripotent state, whereas human ESCs require fibroblast growth factors (FGF), BMP, and transforming growth factor- $\beta$ (TGF- $\beta$ ) to maintain pluripotency.

A fine-tune of growth factor-induced and cytoskeletonassociated cues are crucial in the maintenance and balance between differentiation and self-renewal in ESCs. These signals ultimately control the levels and actions of a core transcriptional circuitry consisting of OCT4 (also known as POU5F1), NANOG and SOX2 (128). YAP and TEAD2 activate the expression of ESC master transcriptional regulators OCT4 and NANOG in mammalian ESCs. Also, nuclear TAZ/YAP activity is required to integrate growth factor signals with these core transcriptional regulators to maintain the ESC pluripotent state. Human ESCs require signals induced by FGFs and members of the TGF $\beta$ family (129). TGF $\beta$ stimulates the action of serine/threonine kinase receptors that phosphorylate and activate the SMAD2/3 class of transcription factors (130). TAZ/YAP proteins form complexes with phosphorylated SMAD2/3 $(123,126)$. In the nucleus, the TAZ/YAP-SMAD2/3 complexes bind TEAD transcription factors, and the core stem cell regulator OCT4, and together mediate the pluripotent state (124). Mechanistically, this complex assembles with factors that make up the nucleosome remodeling and deacetylation $(\mathrm{NuRD})$ complex to buffer the expression of pluripotency genes and repress genes that define mesoendoderm. Upon mesoendoderm specification, the TAZ/YAP-TEAD-OCT4 complex dissociates from the SMADs, allowing the SMADs to activate the forkhead transcription factor FOXH1 and drive differentiation (124).

Similarly, mouse ESCs also require precise Yap levels to maintain their pluripotent state. Knockdown of Yap in mouse ESCs leads to loss of OCT4 and SOX2 expression, and consequent differentiation (125).

YAP may induce the expression of pluripotency-associated genes, which promote ESC self-renewal. It is suggested that YAP is dispensable for self-renewal but is required for the differentiation of ESCs. Knockdown or knockout of Yap does not alter ESC self-renewal but impairs their differentiation $(131,132)$. TAZ and the TEADs are also dispensable for ESC self-renewal (132). Deletion of Lats2 in ESCs impairs their pluripotency and ability to differentiate (133). The discrepancy among these studies is likely due to the presence of unknown factors, which affect the Hippo pathway in different cell lines, as well as variations in cell culture and experiments.

\section{YAP in Induced Pluripotent Stem Cells (iPSCs)}

The role of YAP in controlling pluripotency is seen in induced pluripotent stem cells (iPSCs), which was established by using the ectopic expression of Oct3/4, Sox2, Klf4, and c-Myc genes closely resemble that of ESCs in phenotype and differentiation potential $(124,134)$. YAP is activated during the reprogramming process of human embryonic fibroblasts into iPSCs, and the addition of YAP to original four factors increases the reprogramming efficiency in mouse embryonic fibroblasts, further confirming a positive role of YAP in stemness (135). As in human ESCs, the interaction between YAP and TEADs directs transcriptional circumstances important for maintaining pluripotency. Ectopic expression of a nuclear-localized mutant YAP promotes mouse ESC self-renewal and increases the efficiency of iPSC reprogramming (125). In human iPSC, knockdown of LATS2 increases the reprogramming efficiency of iPSCs (136). Moreover, a recent study reported the success in reprograming of iPSCs derived from primary human amniotic epithelial cells (HuAECs) through the introduction of OSY (OCT3/4, SOX2, and YAP) to activate the Hippo-Yap signaling pathway (135).

While the nuclear TAZ/YAP complex exhibits crucial roles in ESCs cultured in vitro, studies using mouse blastocysts indicate that TAZ/YAP is in the cytoplasm of the ICM, the region from which ESCs are derived. The observations suggest that pluripotent ESCs exist very transiently in vivo, and that changes in TAZ/YAP localization might provide a mechanism to integrate microenvironmental cues during cell differentiation. Indeed, a mechanical microenvironment dramatically affects stem cell fate (137).

\section{HIPPO SIGNALING IN TUMORIGENESIS AND TUMOR INITIATING CELLS}

The Hippo pathway is critical in homeostasis, and is utilized by cancer cells for growth and progression. Mechanically, cytosolic phosphorylated YAP/TAZ inhibits tumor growth. Upon dephosphorylation, YAP/TAZ undergoes nuclear accumulation and promotes cell and tumor growth. In mouse, longterm YAP activation results in liver cell transformation and tumor development (138). The oncogenic activity of YAP is highly dependent on TEAD-mediated gene transcription. Dominant negative TEAD inhibits YAP-induced liver cancer by sequestering YAP and TAZ in the cytoplasm (138). Clearly, these findings suggest that the action of YAP/TAZ fails to distinguish what is a normal or an abnormal cellular event, and there is no apparent regulatory mechanism in the nucleus to override the action of YAP/TAZ.

\section{YAP/TAZ Gene Alterations and Protein Fusions}

Upregulated expression or nuclear accumulation of YAP/TAZ has been observed in various types of human cancers, including liver, breast, lung, colon, ovary (139-141). Gene alteration and fusion genes involving YAP and TAZ have also been examined in human cancers. For example, NF2 mutation causes neurofibromatosis 2 , schwannomas, meningiomas, and 
mesothelioma (142). Heterozygous deletion of Yap completely blocks liver tumorigenesis in Nrf2 knockout mice (47). Statistics with clinical epithelioid hemangioendotheliomas specimens revealed that almost all cases carry TAZ-CAMTA1, TAZ-FOSB, or YAP-TFE3 fusion genes $(101,143-147)$. Besides, in a portion of ependymal tumors, YAP gene is found to fuse with MAMLD1 or C11orf95 $(145,148)$.

A similar finding is also observed in neuroblastoma, neural stem cells carrying the YAP-C11orf95 fusion gene tent to effectively form brain tumors when transplanted into mice (148). In addition, a familial YAP point mutation (R331W) has also been reported to correlate with a high incidence of lung adenocarcinomas (149). Although in these fusion genes, YAP/TAZ proteins are not unabridged, all YAP/TAZ fusions proteins preserve their $N$-terminal TEAD binding domain. This indicates that the fusion proteins still have the binding ability to TEAD and are able to activate the TEAD-dependent transcriptional program for promoting tumorigenesis. Aberrant mutations of components within the Hippo pathway affect the function of YAP/TAZ leading to oncogenesis. LATS1/2 mutations or gene fusion, which may cause YAP/TAZ activation, have also been sporadically identified in different cancers (150-154). Evidence of the Hippo pathway in tumorigenesis based on mouse models is summarized in Table 2. In addition, crosstalk with other cancer-related signaling pathways, such as KRAS, APC, and $L K B 1$ mutations, have all been reported to contribute to upregulate the YAP/TAZ activity in cancers (156-158).

\section{YAP/TAZ in Cancer Metastasis}

Cancer metastasis is responsible for a huge portion of cancerassociated deaths. It has been reported that high YAP or TAZ activity enables the cells to escape contact inhibition and anoikis, and support anchorage-independent growth (55, 156, 159).

TABLE 2 | Genetic alteration of Hippo pathway in human cancer.

\begin{tabular}{|c|c|c|c|}
\hline Gene & Alteration & Cancer type & References \\
\hline NF2 & Mutation or deletion & $\begin{array}{l}\text { Mesothelioma } \\
\text { Neurofibromatosis type } 2 \\
\text { Schwannoma } \\
\text { Meningioma }\end{array}$ & $(142)$ \\
\hline \multirow[t]{3}{*}{ LATS1/2 } & $\begin{array}{l}\text { Gene Fusion } \\
(\text { LATS1-PSEN1) }\end{array}$ & Mesothelioma & $(154)$ \\
\hline & LATS2 deletion & Mesothelioma & $(152)$ \\
\hline & LATS2 mutation & Sporadic in different cancers & $(151)$ \\
\hline \multirow[t]{4}{*}{ YAP } & Amplification & $\begin{array}{l}\text { Hepatocellular carcinoma } \\
\text { Medulloblastoma } \\
\text { Esophageal squamous cell } \\
\text { carcinoma }\end{array}$ & $(153)$ \\
\hline & Mutation (R331W) & Lung adenocarcinoma & $(149)$ \\
\hline & $\begin{array}{l}\text { Gene Fusion } \\
\text { (YAP-TFE3, } \\
\text { YAP-ESR1, } \\
\text { YAP-C110rf95, and } \\
\text { YAP-MAMLD1) }\end{array}$ & $\begin{array}{l}\text { Epithelioid } \\
\text { Hemangioendothelioma } \\
\text { Luminal breast cancer } \\
\text { Ependymal tumors }\end{array}$ & $\begin{array}{l}(146) \\
(144) \\
(147) \\
(145) \\
(148)\end{array}$ \\
\hline & Deletion & Hematological cancer & $(155)$ \\
\hline$T A Z$ & $\begin{array}{l}\text { Gene Fusion } \\
\text { (TAZ-CAMTA1, and } \\
\text { TAZ-FOSB) }\end{array}$ & $\begin{array}{l}\text { Epithelioid } \\
\text { hemangioendothelioma }\end{array}$ & $\begin{array}{l}(143) \\
(144) \\
(101)\end{array}$ \\
\hline
\end{tabular}

YAP or TAZ activation promotes metastasis by influencing many of processes related to metastasis, such as epithelial-tomesenchymal transition (EMT), invasion, extravasation, and escaping from the immune system. Substantial evidence indicates that in addition to promoting tumor growth, YAP activation is sufficient to drive cancer metastasis (160). For example, YAP promotes tumor metastasis through inducing the expression of Zinc finger E-box-binding homeobox 1 and 2 (ZEB1/2) for stimulating EMT (161). Activation of YAP through the loss of leukemia inhibitory factor receptor (LIFR) promotes metastatic colonization of breast cancer cells $(162,163)$. In fact, YAP/TAZ and TEADs in metastasis of numerous cancer types have also been implied, including melanoma (162), lung cancer (164166) breast cancer (163, 167-169), cholangiocarcinoma (170), gastric cancer $(171,172)$, ovarian cancer (173), colorectal cancer $(174,175)$. Clinical data showed that YAP or TAZ expression or nuclear localization is increased in metastatic tumors compared to primary tumors in pancreatic cancer (176), breast cancer $(177,178)$, and prostate cancer (179).

\section{YAP/TAZ in Drug Resistance and Tumor Relapse}

In addition to metastasis, drug resistance, and tumor relapse are the hard cracking nuts for cancer therapy. YAP/TAZ activity also correlates with drug resistance and cancer recurrence. One study has analyzed the gene expression profile of several cancer cell lines, and uncovered the immune checkpoint molecule PDL1 as a target of Hippo signaling (180). In this process, PD-L1 expression is suppressed by the upstream kinases MST1/2 and LATS1/2 of the Hippo pathway, while TAZ and YAP enhance PD-L1 levels in breast and lung cancer cell lines. Critically, TAZ-induced PD-L1 upregulation in human cancer cells is sufficient to inhibit $\mathrm{T}$ cell function (181). Further, in vitro studies indicate that cultured breast cancer cells exhibit high YAP/TAZ activity and confer drug-resistance to many routinely used chemotherapeutic drugs, such as taxol, 5-fluorouracil, and doxorubicin (182-184). Lung and colon cancer cells with high YAP activity exhibit resistance to RAF- and MEK-targeted therapies (185). Furthermore, tamoxifen is one of the commonly used chemo-drug for the treatment of estrogen receptor (ER)positive breast cancer. Recent study has shown that tamoxifen may activate YAP/TAZ by stimulating the membrane estrogen receptor GPER, which may explain why certain ER-positive breast cancers are insensitive to tamoxifen (186). Elevated gene expression of YAP is associated with cancer relapse in KRASdriven colon and pancreatic cancers $(155,187)$. Taken together, inhibition of YAP/TAZ not only restrains tumorigenesis and tumor progression, but also has the potential to sensitize tumor cells to drugs in chemotherapies or target therapies and prevent cancer recurrence.

\section{Tumor Initiating Cells and the Hippo Pathway}

A special subpopulation of highly tumorigenic cells, known as tumor initiating cells (TICs), has been proposed to harbor unique properties such as self-renewal and tumor-initiating potential. TICs are believed to be responsible for drug resistance, metastasis, recurrence, and major causes of cancer death 
(188). Chemotherapy and target therapy are currently the major treatments for patients with cancer. Unfortunately, these conventional therapies often fail to eradicate TICs, thereby permitting TIC-mediated cancer relapse. The YAP/TAZ complex has been shown to be a key regulator of TICs in various cancer types.

Tumor cells with a high YAP/TAZ activity display resistance to chemotherapeutics. YAP activation promotes the transformation of prostate epithelial cells to become an androgen-insensitive state and castration resistance in vivo (189). YAP facilitates the dedifferentiation and expands undifferentiated stem/progenitor cells, e.g., transformation of the mature hepatocytes into progenitor cells (89). YAP/TAZ activation leading to induction of TIC properties has been observed in multiple human cancers. In breast cancer, YAP occupies mammary stem cell signature gene promoters to induce breast TICs (190). TAZ expression is enriched in breast TICs with CD $44^{\text {high }} / \mathrm{CD} 24^{\text {low }}$ phenotype, which is required to sustain self-renewal and tumor-initiating properties (191). In addition, glucocorticoid hormone-induced YAP activation expands chemo-resistant breast TICs.

YAP is one of the major inducers of TIC properties, which directly upregulates the SOX9 transcription factor for controlling the differentiation of many cell types (190). Similarly, in osteosarcoma and glioblastoma, SOX2 promotes YAP activation to maintain TICs capacity (192). Glucocorticoid hormoneinduced YAP activation induces expansion of chemo-resistance in breast TICs (191). In clinical specimens of urothelial carcinoma of bladder (UCB), the expression of YAP positively correlates with the expression of SOX2 and COX2. The tumor cells draw support from the proinflammatory role of the COX2/PGE2 pathway, and the growth-regulatory YAP recruits the stem cell factor SOX2 in expanding and sustaining the accumulation of TICs. In mouse xenograft study, activation of the COX2/PGE2 and YAP pathways promote acquired resistance to EGFR inhibitors (193). Taken together, YAP/TAZ plays an important role in tumorigenesis, cancer progression, and TICs maintenance. TICs are highly related to tumor spread, drugresistance, and cancer relapse, and are responsible for treatment failure and poor prognosis. TIC-specific regulatory mechanisms of YAP/TAZ and Hippo pathway remain further elucidation.

\section{TARGETING THE HIPPO SIGNALING PATHWAY FOR THERAPY}

Nowadays, cancer becomes one of the notorious leading causes of mortality globally. A plenty of studies indicate that the Hippo pathway plays a key role in tumorigenesis. Aberrant Hippo pathway activity promotes cancer cells growth and leads cancer cells to acquire drug resistance (183). YAP and TAZ activity is often upregulated in cancer cells, but their activity is typically silent in normal resting tissue, suggesting that systemic YAP/TAZ inhibition allows cancer treatment without causing significant side effects $(30,117)$ (Figure 5).

\section{Small Molecular Drugs}

Small molecular drugs are intended to disrupt the YAP/TAZTEAD complex and block the complex-mediated gene transcription. Verteporfin, an FDA-approved photosensitizer of porphyrin family molecules for treating macular degeneration, is currently the most widely used YAP inhibitor in research laboratories (138). Verteporfin binds YAP and disrupts the binding of YAP/TAZ with TEADs, and, alternatively, upregulates 14-3-3 expression to facilitate YAP/TAZ degradation (194196). Verteporfin suppresses liver overgrowth induced by YAP overexpression or NF2 inactivation in mice (138). However, YAPindependent cytotoxic effect of Verteporfin has been reported (197-199). Moreover, pharmacological modulation of signal transduction pathways that crosstalk with the Hippo pathway or inhibition of YAP/TAZ target genes by combination therapy may provide promising approaches to target YAP/TAZ activity. Together, the potential of YAP/TAZ-TEAD as a therapeutic target may improve the current treatment strategies (200-202).

\section{Boosting the Hippo Pathway}

In stark contrast, given the fact that the Hippo pathway is essential for organ development and regeneration, manipulating the components of the Hippo pathway would enhance drug design for regenerative medicine. Regenerative medicine refers to medical approaches to promote functional repair and regeneration of damaged tissues or organs, the practices can be separated into two major parts to reach the goal. One is stimulation of intrinsic repair process by molecular therapy, and the other is transplantation of tissues or stem/progenitor cells cultured in laboratories. Clinical doctors always face the hard situation with the shortage of donors compared to the increasing needs of tissue/organ transplantation. Thus, development of novel regenerative therapy is imperative.

YAP/TAZ activity is generally high during embryonic development, but soon declines to a basal level after birth. Upon tissue injury, YAP/TAZ activity is immediately reactivated in a transient manner. Transient activation of YAP/TAZ promotes the expansion of progenitors or dedifferentiation of mature cells to facilitate tissue regeneration. Thus, activation of YAP/TAZ is a potential strategy to promote tissue regeneration (Figure 5).

Inhibition of upstream kinases, such as MAP4K4, MST1/2, or LATS1/2, in the Hippo pathway, represents an ideal approach to induce YAP/TAZ activity and facilitate the process of tissue repair or regeneration, and possibly for treating degenerative diseases. Systematic or local delivery of Hippo pathway kinase inhibitors can induce this regenerative program. Recently, an MST1/2 inhibitor has been discovered and exhibits a good response in promoting liver and intestinal regeneration (203). Gene therapy is also an effective strategy (204), either by regulating YAP by the viral or viral-free system or introducing siRNA or miRNA for tissue regeneration (205).

Transplantation of in vitro expanded progenitors, organoids, or tissues are feasible methods. In recent years, a variety of organoids have been generated successfully in vitro, including stomach, liver, kidney, lung, intestine, brain, and retina (206). Nonetheless, it is a puzzle to command the complicated biological parameters, including cell types, organization, and microenvironment within an organoid system (207). Supporting evidence revealed the outstanding effects of YAP/TAZ transient activation in dedifferentiating mammary, neuronal, and pancreatic cells into a progenitor 
A
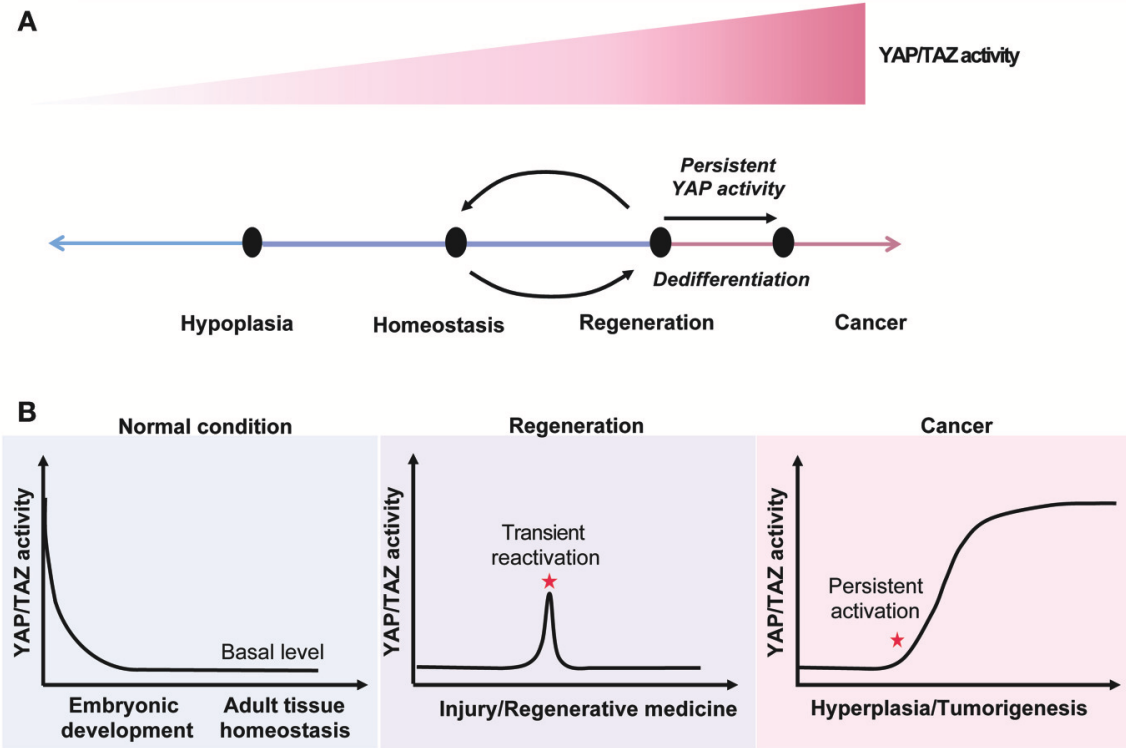

FIGURE 5 | The Hippo signaling in tissue homeostasis, regeneration and cancer. (A) YAP/TAZ activity regulates tissue homeostasis and modulates the cell state. (B) YAP/TAZ activity is declined to a relative low level after birth. The YAP/TAZ activity is reactivated after tissue injuries and constitutively upregulated in cancer.

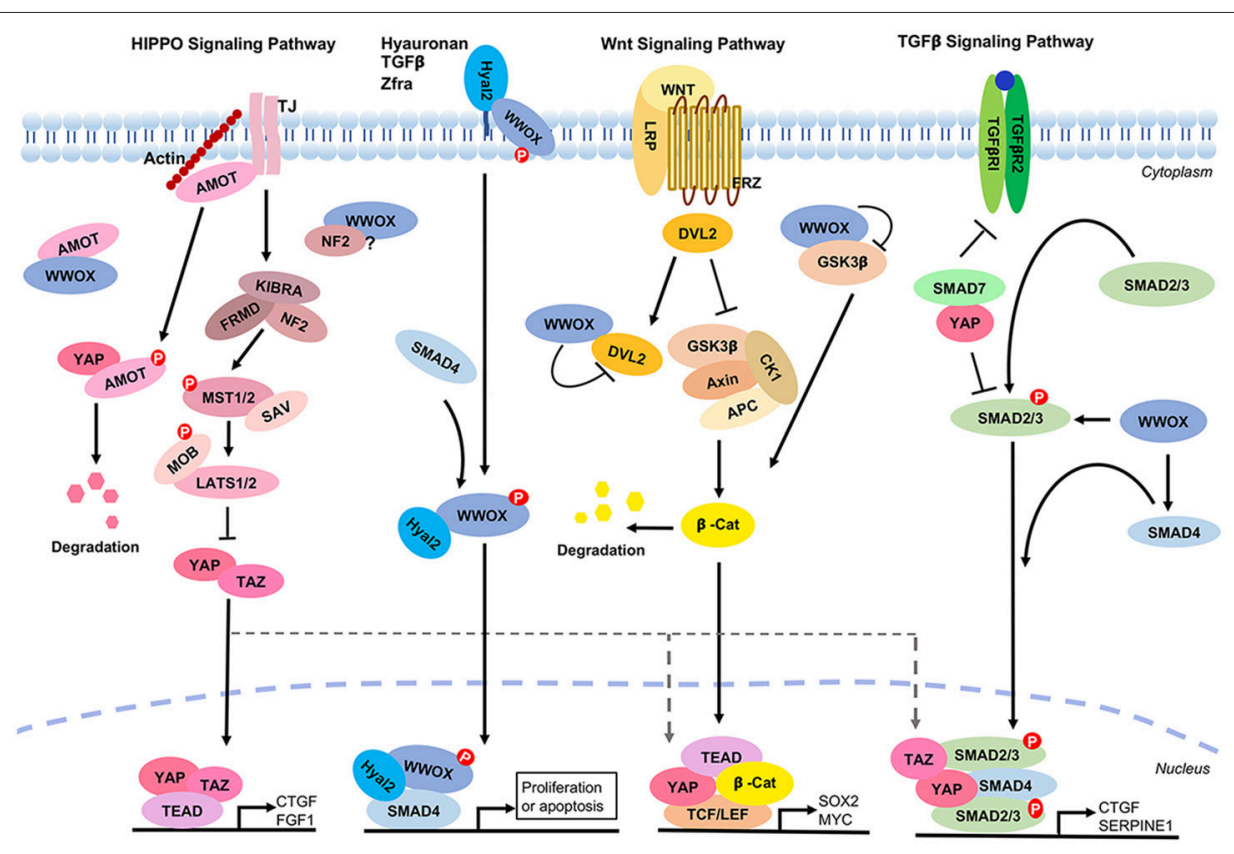

FIGURE 6 | WWOX controls TGF- $\beta$, Hyal-2, and Wnt signaling pathways that cross talks with the Hippo signaling. A panel is shown for the Hippo, Hyal-2/WWOX/Smad4, Wnt and TGF- $\beta$ signaling pathways. WWOX supports the Hyal-2 and TGF- $\beta$ signal pathways. However, WWOX blocks the Wnt pathway by binding GSK3 $\beta$ and DVL2. WWOX binds AMOT and probably NF2 in the Hippo pathway, whereas the functional consequence of this binding is unknown.

state, and these cells can be used to generate organoids for transplantation (208). Thus, modulating the Hippo pathway may represent a useful strategy for enrichment of progenitor cells or differentiated organoids for regenerative medicine.
In conclusion, the marvelous regulation of the Hippo pathway and YAP/TAZ in progenitor expansion and cell differentiation is forceful and feasible for promoting tissue regeneration. The Hippo pathway is generally considered as an effector in tumor suppression, and many anticancer drugs been developed (209). 
In facilitating regenerative medicine, small molecular drugs for Hippo activation can be implemented.

\section{IS WW DOMAIN AN ALL-TIME PARTY COORDINATOR?}

\section{All-Time Party Coordinator?}

The WW domain is a well-known structural module that is responsible for protein/protein binding interactions $(210,211)$. The WW domain has three anti-parallel beta-sheets, which appears to facilitate protein/protein binding. In the human proteome, there are at least $52 \mathrm{WW}$ domain-containing proteins, and more than 10,000 among all species. Each protein may have one or up to 4 repeats of WW domains in the amino acid sequence. The WW domain binds a proline-rich motif such as PPxY or PPPY in a target protein. Phosphorylation in specific residues within the WW domain enhances its binding capability as seen in WWOX $(210,211)$. In the Hippo pathway (212), there are $4 \mathrm{WW}$ domain-containing proteins, namely SAV, KIBRA, YAP, and TAZ. Amazingly, YAP, TAZ, and/or the YAP/TAZ complex binds approximately 20 proteins, including p73, RUNXs, SMADs, PRGP2, Pax3, ErbB4, ASPP2, AMOTs, Wbp2, $\beta$-catenin, Parafibromin, ROR $\alpha$, and SET1A (212). Without a doubt, WW domain can be considered as an all-time party coordinator. Each WW domain-containing protein interacts with many proteins. The binding signals biological events for cell survival, death, and others. However, how can a single cell handle so many downstream signaling targets from an upstream stimulator during a single signaling run? And, this may end up with desired outcomes. Presumably, a specific downstream effector(s) stands out to solely carry out the signaling mission and exhibits the results, and meanwhile eliminates the outcome from other signaling co-effectors.
The signaling branches derived from the upstream signaling could exhibit conflicts among the downstream effectors. For example, Hippo pathway has a close connection with SMAD signaling (213). YAP enhances pSmad1-dependent gene transcription. In contrast, as a self-control mechanism, YAP promotes Smad7-mediated inhibition of TGF- $\beta$ signaling (213). Nonetheless, there is a converge among Wnt, TGF- $\beta$, and YAP/TAZ pathway $(214,215)$. YAP takes the center of the signaling stage by participating in the gene transcription in the nucleus among these pathways (216).

\section{Tumor Suppressor WWOX in the TGF- $\beta$, Hyal-2, and Wnt Signaling That Cross Talks With the Hippo Pathway}

Tumor suppressor WWOX is a potent inhibitor of the Wnt/ $\beta$ catenin signaling via binding with Disheveled Dvl-2 to enforce the cytoplasmic retention of Dvl-2 and increased degradation of $\beta$-catenin $(210,217)$. WWOX binds $\operatorname{Smad} 2,3$, and 4 in the TGF$\beta /$ Smad and Hyal-2 signal pathways to modulate cell proliferation or death (218-220) (Figure 6). Hyaluronan, TGF- $\beta$ and Zfra (zinc finger-like protein that regulates apoptosis) utilize the Hyal$2 / \mathrm{WWOX} / \mathrm{Smad} 4$ pathway $(218,219)$. Activation of the Wnt/ $\beta$ catenin signaling allows nuclear translocation of TAZ to carry out gene transcription with TEAD. WWOX intervenes the event by directly binding and blocking the function of GSK-3 $\beta$ in the

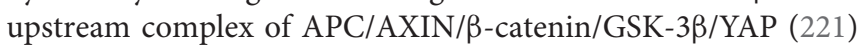
(Figure 6). Indeed, YAP is involved in the transcription stage of the TGF- $\beta$, Wnt/ $\beta$-catenin and Hippo signaling (222). WWOX controls the aforementioned signaling from the upstream steps and thereby affects the function of YAP in the downstream. Indeed, WWOX binds AMOT and probably NF2 in the upstream of the Hippo pathway.

TABLE 3 | Outstanding questions.

Gene and proteins

Gene and protein isoforms

WW domain proteins

Upstream of the Hippo signal pathway

The Hippo signal flow
- What are the tissue-specific gene products from alternative splicing for the Hippo pathway?

- The Hippo pathway is evolutionarily conserved. Why do these proteins in the pathway readily respond to diversified stimulators? What are the key purposes for the biological outcomes?

- Do proteins isoforms compete with each other during the Hippo signaling?

- How can each cell handle the diversified signals? Signal integration or elimination?

- What are the functional differences between two-WW-domain YAP1 and one-WW-domain YAP2?

- Further, YAP1 has 4 isoforms due to alternative splicing in the TAD domain. What are the functional differences among these proteins in terms of regulation of gene expression? Can which isoform act as a decoy protein to block the signal flow?

- KIBRA participates in both the Wnt/Hedgehog/Notch and Hippo signaling pathways. Which pathway does KIBRA have the most effect on the biological outcome?

- KIBRA binds LATS1 and LATS2. Which complex KIBRA/LATS1 or KIBRA/LATS2 is more effective in blocking YAP/TAZ?

- SAV1 binds MST1 and promotes apoptosis. How does apoptosis get activated?

- Which upstream signaling molecules act in concert to suppress the YAP/TAZ activity, and which are in antagonistic manners? Which stimulator can override the signaling from others?

- Since the pathway is sensitive to diversified stimulators, are there unidentified agonists?

- How many signal proteins in the Hippo pathway readily crosstalk with proteins from Wnt, TGF- $\beta$, and ERK pathways? Tumor suppressor WWOX interacts with these pathways. Can WWOX act as a modulator for optimizing the signaling outcomes?

- Lacking a real-time mode for cellular signaling pathways is hard to unravel the hidden events (e.g., promoter activation, protein/protein interactions, and etc.). For a signaling with so many branches in the downstream, or a signaling with many upstream stimulators, is there a dominant signal flow? 


\section{Protein Isoforms}

$\mathrm{WW}$-domain isoforms could be another issue. Some proteins have one WW domain, and others have more than one. YAP1 has two WW domain and YAP2 has one. YAP1 has up to 9 isoforms according to the NCBI protein database. For a single protein possessing more than one WW domains in the amino acid sequence, these WW domains may act in a concerted manner to boost the protein function (223). However, during the Hippo signaling, it is not clear which YAP isoform is the key executor to generate the intended outcome in a specific cell. The complexity of the signaling events can be observed not only in the Hippo signaling pathway but also in many signaling pathways (e.g., TGF- $\beta$, MAPK/ERK, and others). Among these pathways, there are crosstalk between each other. Knockdown of a single protein could generate a desired phenotype. However, the observation could be a sum of many signaling pathways.

\section{CONCLUDING REMARKS AND OUTSTANDING QUESTIONS}

In summary, we have addressed the role of Hippo pathway in the regulation of embryonic development, organ growth, tissue regeneration, stem cell pluripotency, and tumorigenesis. As detailed in the above section, our concerns mainly point to the pathway-regulated biological effects and ultimate outcomes.

\section{REFERENCES}

1. Yu F-X, Zhang Y, Park HW, Jewell JL, Chen Q, Deng Y, et al. Protein kinase A activates the Hippo pathway to modulate cell proliferation and differentiation. Genes Dev. (2013) 27:1223-32. doi: 10.1101/gad.219402.113

2. Zhang K, Hu Z, Qi H, Shi Z, Chang Y, Yao Q, et al. G-proteincoupled receptors mediate $\omega-3$ PUFAs-inhibited colorectal cancer by activating the Hippo pathway. Oncotarget (2016) 7:58315-30. doi: 10.18632/oncotarget.11089

3. Wang Z, Liu P, Zhou X, Wang T, Feng X, Sun Y-P, et al. Endothelin Promotes Colorectal Tumorigenesis by Activating YAP/TAZ. Cancer Res. (2017) 77:2413-23. doi: 10.1158/0008-5472.CAN-16-3229

4. Wu H, Wei L, Fan F, Ji S, Zhang S, Geng J, et al. Integration of Hippo signalling and the unfolded protein response to restrain liver overgrowth and tumorigenesis. Nat Commun. (2015) 6:6239. doi: 10.1038/ncomms7239

5. Yu F-X, Guan K-L. The Hippo pathway: regulators and regulations. Genes Dev. (2013) 27:355-71. doi: 10.1101/gad.210773.112

6. Pan D. The hippo signaling pathway in development and cancer. Dev Cell (2010) 19:491-505. doi: 10.1016/j.devcel.2010.09.011

7. Wang Y, Yu A, Yu F-X. The Hippo pathway in tissue homeostasis and regeneration. Protein Cell (2017) 8:349-59. doi: 10.1007/s13238-017-0371-0

8. Fu V, Plouffe, Steven W, Guan K-L. The Hippo pathway in organ development, homeostasis, and regeneration. Curr Opin Cell Biol. (2017) 49:99-107. doi: 10.1016/j.ceb.2017.12.012

9. Justice RW, Zilian O, Woods DF, Noll M, Bryant PJ. The Drosophila tumor suppressor gene warts encodes a homolog of human myotonic dystrophy kinase and is required for the control of cell shape and proliferation. Genes Dev. (1995) 9:534-46. doi: 10.1101/gad.9.5.534

10. Xu T, Wang W, Sheng Z, Stewart RA, Yu W. Identifying tumor suppressors in genetic mosaics: the Drosophila lats gene encodes a putative protein kinase. Development (1995) 121:1053-63.

11. Tapon N, Harvey KF, Bell DW, Wahrer DCR, Schiripo TA, Haber DA, et al. Salvador promotes both cell cycle exit and apoptosis in Drosophila
Several outstanding questions are listed in the Table 3. Our hope is that more sophisticated tools are needed to predict and solve problems associated with multiple signal stimulators, crosstalk among the signal proteins in the pathway with others, functional efficacy of protein isoforms in the signaling, and problem-solving associated with conflict signaling.

\section{AUTHOR CONTRIBUTIONS}

Y-AC and C-YL carried out the literature review, prepared schematic graphs, and wrote the manuscript. T-YC participated in drafting and prepared high-resolution figures and organized the references section. N-SC, S-HP, and H-FC provided advisory points to the first and other authors. N-SC thoroughly revised added challenging concepts and outstanding questions, developed new ideas, and completed the final version of the manuscript. All authors read and approved the final version.

\section{FUNDING}

Research supports to N-SC were from the Ministry of Science and Technology, Taiwan (MOST 105-2320-B-006-046, 105-2320-B006-036, 106-2320-B-006-061, 106-2320-B-006-017, 107-2320B-006-058-MY3, 107-2320-B-006-005) and the National Health Research Institutes, Taiwan (NHRI-EX107-10734NI), and MOST 107-2314-B-002-150-MY3 to H-FC. and is mutated in human cancer cell lines. Cell (2002) 110:467-78. doi: 10.1016/S0092-8674(02)00824-3

12. Harvey KF, Pfleger CM, Hariharan IK. The Drosophila Mst ortholog, hippo, restricts growth and cell proliferation and promotes apoptosis. Cell (2003) 114:457-67. doi: 10.1016/s0092-8674(03)00557-9

13. Udan RS, Kango-Singh M, Nolo R, Tao C, Halder G. Hippo promotes proliferation arrest and apoptosis in the Salvador/Warts pathway. Nat Cell Biol. (2003) 5:914-20. doi: 10.1038/ncb1050

14. Wu S, Huang J, Dong J, Pan D. Hippo Encodes a Ste-20 family protein kinase that restricts cell proliferation and promotes apoptosis in conjunction with salvador and warts. Cell (2003) 114:445-56. doi: 10.1016/s0092-8674(03)00549-x

15. Lai Z-C, Wei X, Shimizu T, Ramos E, Rohrbaugh M, Nikolaidis N, et al. Control of cell proliferation and apoptosis by mob as tumor suppressor, mats. Cell (2005) 120:675-85. doi: 10.1016/j.cell.2004.12.036

16. Huang J, Wu S, Barrera J, Matthews K, Pan D. The Hippo signaling pathway coordinately regulates cell proliferation and apoptosis by inactivating Yorkie, the Drosophila Homolog of YAP. Cell (2005) 122:421-34. doi: 10.1016/j.cell.2005.06.007

17. Dong J, Feldmann G, Huang J, Wu S, Zhang N, Comerford SA, et al. Elucidation of a universal size-control mechanism in Drosophila and mammals. Cell (2007) 130:1120-33. doi: 10.1016/j.cell.2007.07.019

18. Chan EH, Nousiainen M, Chalamalasetty RB, Schäfer A, Nigg EA, Sillje HH. The Ste20-like kinase Mst2 activates the human large tumor suppressor kinase Lats1. Oncogene (2005) 24:2076-86. doi: 10.1038/sj.onc.12 08445

19. Callus BA, Verhagen AM, Vaux DL. Association of mammalian sterile twenty kinases, Mst1 and Mst2, with hSalvador via C-terminal coiled-coil domains, leads to its stabilization and phosphorylation. FEBS J. (2006) 273:4264-76. doi: $10.1111 /$ j.1742-4658.2006.05427.x

20. Zhao B, Li L, Tumaneng K, Wang C-Y, Guan K-L. A coordinated phosphorylation by Lats and CK1 regulates YAP stability through SCF(betaTRCP). Genes Dev. (2010) 24:72-85. doi: 10.1101/gad.1843810 
21. Zhao B, Ye X, Yu J, Li L, Li W, Li S, et al. TEAD mediates YAPdependent gene induction and growth control. Genes Dev. (2008) 22:196271. doi: $10.1101 /$ gad.1664408

22. Guo T, Lu Y, Li P, Yin M-X, Lv D, Zhang W, et al. A novel partner of Scalloped regulates Hippo signaling via antagonizing Scalloped-Yorkie activity. Cell Res. (2013) 23:1201-14. doi: 10.1038/cr.2013.120

23. Li Q, Li S, Mana-Capelli S, Roth Flach RJ, Danai LV, Amcheslavsky A, et al. The conserved misshapen-warts-Yorkie pathway acts in enteroblasts to regulate intestinal stem cells in Drosophila. Dev Cell (2014) 31:291-304. doi: 10.1016/j.devcel.2014.09.012

24. Yin F, Yu J, Zheng Y, Chen Q, Zhang N, Pan D. Spatial organization of Hippo signaling at the plasma membrane mediated by the tumor suppressor Merlin/NF2. Cell (2013) 154:1342-55. doi: 10.1016/j.cell.2013.08.025

25. Baumgartner R, Poernbacher I, Buser N, Hafen E, Stocker H. The WW domain protein Kibra acts upstream of Hippo in Drosophila. Dev Cell (2010) 18:309-16. doi: 10.1016/j.devcel.2009.12.013

26. Yu J, Zheng Y, Dong J, Klusza S, Deng WM, Pan D. Kibra functions as a tumor suppressor protein that regulates Hippo signaling in conjunction with Merlin and Expanded. Dev Cell (2010) 18:288-99. doi: 10.1016/j.devcel.2009.12.012

27. DeRan M, Yang J, Shen CH, Peters EC, Fitamant J, Chan P, et al. Energy stress regulates hippo-YAP signaling involving AMPK-mediated regulation of angiomotin-like 1 protein. Cell Rep. (2014) 9:495-503. doi: 10.1016/j.celrep.2014.09.036

28. Praskova M, Khoklatchev A, Ortiz-vega S, Avruch J. Regulation of the MST1 kinase by autophosphorylation, by the growth inhibitory proteins, RASSF1 and NORE1, and by Ras. Biochem J. (2004) 381:453-62. doi: 10.1042/BJ20040025

29. Praskova M, Xia F, Avruch J. MOBKL1A/MOBKL1B phosphorylation by MST1 and MST2 inhibits cell proliferation. Curr Biol. (2008) 18:311-21. doi: 10.1016/j.cub.2008.02.006

30. Camargo FD, Gokhale S, Johnnidis JB, Fu D, Bell GW, Jaenisch R, et al. YAP1 increases organ size and expands undifferentiated progenitor cells. Curr Biol. (2007) 17:2054-60. doi: 10.1016/j.cub.2007.10.039

31. Ramos A, Camargo FD. The Hippo signaling pathway and stem cell biology. Trends Cell Biol. (2012) 22:339-46. doi: 10.1016/j.tcb.2012.04.006

32. Mo J-S, Park HW, Guan K-L. The Hippo signaling pathway in stem cell biology and cancer. EMBO Rep. (2014) 15:642-56. doi: 10.15252/embr.201438638

33. Panciera T, Azzolin L, Cordenonsi M, Piccolo S. Mechanobiology of YAP and TAZ in physiology and disease. Nat Rev Mol Cell Biol. (2017) 18:758-70. doi: $10.1038 / \mathrm{nrm} .2017 .87$

34. Fulford A, Tapon N, Ribeiro PS. Upstairs, downstairs: spatial regulation of Hippo signalling. Curr Opin Cell Biol. (2017) 51:22-32. doi: 10.1016/j.ceb.2017.10.006

35. Low BC, Pan CQ, Shivashankar GV, Bershadsky A, Sudol M, Sheetz M. YAP/TAZ as mechanosensors and mechanotransducers in regulating organ size and tumor growth. FEBS Lett. (2014) 588:2663-70. doi: 10.1016/j.febslet.2014.04.012

36. Wu Y, Griffin EE. Regulation of Cell Polarity by PAR-1/MARK Kinase. Curr Top Dev Biol. (2017) 123:365-97. doi: 10.1016/bs.ctdb.2016.11.001

37. Wang L, Chen Z, Wang Y, Chang D, Su L, Guo Y, et al. TR1 promotes cell proliferation and inhibits apoptosis through cyclin A and CTGF regulation in non-small cell lung cancer. Tumour Biol. (2004) 35:463-8. doi: 10.1007/s13277-013-1064-9

38. Chakraborty S, Njah K, Pobbati AV, Lim YB, Raju A, Lakshmanan M, et al. Agrin as a mechanotransduction signal regulating YAP through the hippo Pathway. Cell Rep. (2017) 18:2464-79. doi: 10.1016/j.celrep.2017.02.041

39. Kim N-G, Koh E, Chen X, Gumbiner BM. E-cadherin mediates contact inhibition of proliferation through Hippo signaling-pathway components. Proc Natl Acad Sci USA. (2011) 108:11930-5. doi: 10.1073/pnas.1103345108

40. Yue T, Tian A, Jiang J. The cell adhesion molecule echinoid functions as a tumor suppressor and upstream regulator of the Hippo signaling pathway. Dev Cell (2012) 22:255-67. doi: 10.1016/j.devcel.2011.12.011

41. Verghese S, Waghmare I, Kwon H, Hanes K, Kango-Singh M. Scribble acts in the Drosophila fat-hippo pathway to regulate warts activity. PLoS ONE (2012) 7:e47173. doi: 10.1371/journal.pone.0047173
42. Richardson HE, Portela M. Tissue growth and tumorigenesis in Drosophila: cell polarity and the Hippo pathway. Curr Opin Cell Biol. (2017) 48:1-9. doi: 10.1016/j.ceb.2017.03.006

43. Konsavage WM, Jr., Yochum GS. Intersection of Hippo/YAP and Wnt/betacatenin signaling pathways. Acta Biochim Biophys Sin. (2013) 45:71-9. doi: 10.1093/abbs/gms084

44. Yu F-X, Zhao B, Panupinthu N, Jewell JL, Lian I, Wang LH, et al. Regulation of the Hippo-YAP pathway by G-protein-coupled receptor signaling. Cell (2012) 150:780-91. doi: 10.1016/j.cell.2012.06.037

45. Tumaneng K, Schlegelmilch K, Russell RC, Yimlamai D, Basnet H, Mahadevan N, et al. YAP mediates crosstalk between the Hippo and PI(3)KTOR pathways by suppressing PTEN via miR-29. Nat Cell Biol. (2012) 14:1322-9. doi: 10.1038/ncb2615

46. Dai X, She P, Chi F, Feng Y, Liu H, Jin D, et al. Phosphorylation of angiomotin by Lats1/2 kinases inhibits F-actin binding, cell migration, and angiogenesis. J Biol Chem. (2013) 288:34041-51. doi: 10.1074/jbc.M113.518019

47. Zhang N, Bai H, David KK, Dong J, Zheng Y, Cai J, et al. The Merlin/NF2 tumor suppressor functions through the YAP oncoprotein to regulate tissue homeostasis in mammals. Dev Cell (2010) 19:27-38. doi: 10.1016/j.devcel.2010.06.015

48. Chan SW, Lim CJ, Guo F, Tan I, Leung T, Hong W. Actin-binding and cell proliferation activities of angiomotin family members are regulated by Hippo pathway-mediated phosphorylation. J Biol Chem. (2013) 288:37296-307. doi: 10.1074/jbc.M113.527598

49. Mana-Capelli S, Paramasivam M, Dutta S, McCollum D. Angiomotins link F-actin architecture to Hippo pathway signaling. Mol Biol Cell (2014) 25:1676-85. doi: 10.1091/mbc.E13-11-0701

50. Liu C-Y, Zha Z-Y, Zhou X, Zhang H, Huang W, Zhao D, et al. The hippo tumor pathway promotes TAZ degradation by phosphorylating a phosphodegron and recruiting the SCF \{beta\}-TrCP E3 ligase. J Biol Chem. (2010) 285:37159-69. doi: 10.1074/jbc.M110.152942

51. Nguyen TH, Kugler JM. Ubiquitin-dependent regulation of the mammalian hippo pathway: therapeutic implications for cancer. Cancers (2018) 10:E121. doi: 10.3390/cancers 10040121

52. Liang N, Zhang C, Dill P, Panasyuk G, Pion D, Koka V, et al. Regulation of YAP by mTOR and autophagy reveals a therapeutic target of tuberous sclerosis complex. J Exp Med. (2014) 211:2249-63. doi: 10.1084/jem.20140341

53. Glantschnig H, Rodan GA, Reszka AA. Mapping of MST1 kinase sites of phosphorylation. Activation and autophosphorylation. J Biol Chem. (2002) 277:42987-96. doi: 10.1074/jbc.M208538200

54. Hergovich A, Schmitz D, Hemmings BA. The human tumour suppressor LATS1 is activated by human MOB1 at the membrane. Biochem Biophys Res Commun. (2006) 345:50-8. doi: 10.1016/j.bbrc.2006.03.244

55. Zhao B, Wei X, Li W, Udan RS, Yang Q, Kim J, et al. Inactivation of YAP oncoprotein by the Hippo pathway is involved in cell contact inhibition and tissue growth control. Genes Dev. (2007) 21:2747-61. doi: $10.1101 /$ gad. 1602907

56. Meng Z, Moroishi T, Mottier-Pavie V, Plouffe SW, Hansen CG, Hong AW, et al. MAP4K family kinases act in parallel to MST1/2 to activate LATS1/2 in the Hippo pathway. Nat Commun. (2015) 6:8357. doi: 10.1038/ncomms9357

57. Zheng Y, Wang W, Liu B, Deng H, Uster E, Pan D. Identification of Happyhour/MAP4K as Alternative Hpo/Mst-like Kinases in the Hippo Kinase Cascade. Dev Cell (2015) 34:642-55. doi: 10.1016/j.devcel.2015.08.014

58. Sudol M, Harvey KF. Modularity in the Hippo signaling pathway. Trends Biochem Sci. (2010) 35:627-33. doi: 10.1016/j.tibs.2010.05.010

59. Sudol M, Bork P, Einbond A, Kastury K, Druck T, Negrini M, et al. Characterization of the mammalian YAP (Yes-associated Protein) gene and its role in defining a novel protein module, the WW domain. J Biol Chem. (1995) 270:14733-41. doi: 10.1074/jbc.270.24.14733

60. Chen HI, Sudol M. The WW domain of Yes-associated protein binds a proline-rich ligand that differs from the consensus established for Src homology 3-binding modules. Proc Natl Acad Sci USA. (1995) 92:7819-23. doi: 10.1073/pnas.92.17.7819

61. Salah Z, Aqeilan RI. WW domain interactions regulate the Hippo tumor suppressor pathway. Cell Death Dis. (2011) 2:e172. doi: $10.1038 /$ cddis. 2011.53 
62. Sudol M. Yes-associated protein (YAP65) is a proline-rich phosphoprotein that binds to the $\mathrm{SH} 3$ domain of the Yes proto-oncogene product. Oncogene (1994) 9:2145-52.

63. Morin-Kensicki EM, Boone BN, Howell M, Stonebraker JR, Teed J, Alb JG, et al. Defects in yolk sac vasculogenesis, chorioallantoic fusion, and embryonic axis elongation in mice with targeted disruption of Yap65. Mol Cell Biol. (2006) 26:77-87. doi: 10.1128/MCB.26.1.77-87.2006

64. Kanai F, Marignani PA, Sarbassova D, Yagi R, Hall RA, Donowitz M, et al. TAZ: a novel transcriptional co-activator regulated by interactions with 14-3-3 and PDZ domain proteins. EMBO J. (2000) 19:6778-91. doi: 10.1093/emboj/19.24.6778

65. Varelas X. The Hippo pathway effectors TAZ and YAP in development, homeostasis and disease. Development (2014) 141:1614-26. doi: $10.1242 /$ dev. 102376

66. Freeman AK, Morrison DK. 14-3-3 Proteins: diverse functions in cell proliferation and cancer progression. Semin Cell Dev Biol. (2011) 22:681-7. doi: 10.1016/j.semcdb.2011.08.009

67. Oka T, Sudol M. Nuclear localization and pro-apoptotic signaling of YAP2 require intact PDZ-binding motif. Genes Cells (2009) 14:607-15. doi: 10.1111/j.1365-2443.2009.01292.x

68. Remue E, Meerschaert K, Oka T, Boucherie C, Vandekerckhove J, Sudol M, et al. TAZ interacts with zonula occludens-1 and-2 proteins in a PDZ-1 dependent manner. FEBS Lett. (2010) 584:4175-80. doi: 10.1016/j.febslet.2010.09.020

69. Koontz LM, Liu-Chittenden Y, Yin F, Zheng Y, Yu J, Huang B, et al. The Hippo effector Yorkie controls normal tissue growth by antagonizing scalloped-mediated default repression. Dev Cell (2013) 25:388401. doi: 10.1016/j.devcel.2013.04.021

70. Zaidi SK, Sullivan AJ, Medina R, Ito Y, van Wijnen AJ, Stein JL, et al. Tyrosine phosphorylation controls Runx2-mediated subnuclear targeting of YAP to repress transcription. EMBO J. (2004) 23:790-9. doi: 10.1038/sj.emboj.7600073

71. Grannas K, Arngarden L, Lonn P, Mazurkiewicz M, Blokzijl A, Zieba A, et al. Crosstalk between Hippo and TGFbeta: subcellular localization of YAP/TAZ/Smad complexes. J Mol Biol. (2015) 427:3407-15. doi: 10.1016/j.jmb.2015.04.015

72. Zanconato F, Forcato M, Battilana G, Azzolin L, Quaranta E, Bodega $\mathrm{B}$, et al. Genome-wide association between YAP/TAZ/TEAD and AP-1 at enhancers drives oncogenic growth. Nat Cell Biol. (2015) 17:1218-27. doi: $10.1038 /$ ncb3216

73. Galli GG, Carrara M, Yuan W-C, Valdes-Quezada C, Gurung B, PepeMooney $\mathrm{B}$, et al. YAP drives growth by controlling transcriptional pause release from dynamic enhancers. Mol Cell (2015) 60:328-37. doi: 10.1016/j.molcel.2015.09.001

74. Stein C, Bardet AF, Roma G, Bergling S, Clay I, Ruchti A, et al. YAP1 exerts its transcriptional control via TEAD-mediated activation of enhancers. PLoS Genet. (2015) 11:e1005465. doi: 10.1371/journal.pgen.1005465

75. Vassilev A, Kaneko KJ, Shu HS, Zhao Y, DePamphilis ML. TEAD/TEF transcription factors utilize the activation domain of YAP65, a Src/Yesassociated protein localized in the cytoplasm Genes Dev. (2002) 15:1229-41. doi: $10.1101 /$ gad. 888601

76. Zhou D, Conrad C, Xia F, Park J-S, Payer B, Yin Y, et al. Mstl and Mst2 maintain hepatocyte quiescence and suppress hepatocellular carcinoma development through inactivation of the Yap1 oncogene. Cancer Cell (2009) 16:425-38. doi: 10.1016/j.ccr.2009.09.026

77. Song H, Mak KK, Topol L, Yun K, Hu, Jianxin, Garrett L, et al. Mammalian Mst1 and Mst2 kinases play essential roles in organ size control and tumor suppression. Proc Natl Acad Sci USA. (2010) 107:1431-6. doi: 10.1073/pnas.0911409107

78. Chen Q, Zhang N, Xie R, Wang W, Cai J, Choi K-S, et al. Homeostatic control of Hippo signaling activity revealed by an endogenous activating mutation in YAP. Genes Dev. (2015) 29:1285-97. doi: 10.1101/gad.264234.115

79. Nishio M, Hamada K, Kawahara K, Sasaki M, Noguchi F, Chiba S, et al. Cancer susceptibility and embryonic lethality in Mobla/1b double-mutant mice. J Clin Invest. (2012) 122:4505-18. doi: 10.1172/JCI63735

80. Zhang W, Gao Y, Li P, Shi Z, Guo T, Li F, et al. VGLL4 functions as a new tumor suppressor in lung cancer by negatively regulating the YAP-TEAD transcriptional complex. Cell Res. (2014) 24:331-43. doi: 10.1038/cr.2014.10
81. Jiao S, Wang H, Shi Z, Dong A, Zhang W, Song X, et al. A peptide mimicking VGLL4 function acts as a YAP antagonist therapy against gastric cancer. Cancer Cell (2014) 25:166-80. doi: 10.1016/j.ccr.2014.01.010

82. Kim M, Kim T, Johnson RL, Lim D-S. Transcriptional co-repressor function of the hippo pathway transducers YAP and TAZ. Cell Rep. (2015) 11:270-82. doi: 10.1016/j.celrep.2015.03.015

83. Chaulk SG, Lattanzi VJ, Hiemer SE, Fahlman RP, Varelas X. The Hippo pathway effectors TAZ/YAP regulate dicer expression and microRNA biogenesis through Let-7. J Biol Chem. (2014) 289:1886-91. doi: $10.1074 /$ jbc.C113.529362

84. Mori M, Triboulet R, Mohseni M, Schlegelmilch K, Shrestha K, Camargo FD, et al. Hippo signaling regulates microprocessor and links celldensity-dependent miRNA biogenesis to cancer. Cell (2014) 156:893-906. doi: 10.1016/j.cell.2013.12.043

85. Shen S, Guo X, Yan H, Lu Y, Ji X, Li L, et al. A miR-130a-YAP positive feedback loop promotes organ size and tumorigenesis. Cell Res. (2015) 25:997-1012. doi: 10.1038/cr.2015.98

86. Plouffe SW, Lin KC, Moore JL, 3rd, Tan FE, Ma S, Ye Z, et al. The Hippo pathway effector proteins YAP and TAZ have both distinct and overlapping functions in the cell. J Biol Chem. (2018) 293:11230-40. doi: $10.1074 /$ jbc.RA118.002715

87. Yu F-X, Zhao B, Guan K-L. Hippo pathway in organ size control, tissue homeostasis, and cancer. Cell (2015) 163:811-28. doi: 10.1016/j.cell.2015.10.044

88. Patel SH, Camargo FD, Yimlamai D. Hippo signaling in the liver regulates organ size, cell fate, and carcinogenesis. Gastroenterology (2017) 152:533-45. doi: 10.1053/j.gastro.2016.10.047

89. Yimlamai D, Christodoulou C, Galli GG, Yanger K, Pepe-Mooney B, Gurung B, et al. Hippo pathway activity influences liver cell fate. Cell (2014) 157:1324-38. doi: 10.1016/j.cell.2014.03.060

90. Del Re DP, Yang Y, Nakano N, Cho J, Zhai P, Yamamoto T, et al. Yesassociated protein isoform 1 (Yap1) promotes cardiomyocyte survival and growth to protect against myocardial ischemic injury. J Biol Chem. (2013) 288:3977-88. doi: 10.1074/jbc.M112.436311

91. Lin Z, von Gise A, Zhou P, Gu F, Ma Q, Jiang J, et al. Cardiacspecific YAP activation improves cardiac function and survival in an experimental murine MI model. Circ Res. (2014) 115:354-63. doi: 10.1161/CIRCRESAHA.115.303632

92. Xin M, Kim Y, Sutherland LB, Murakami M, Qi X, McAnally J, et al. Hippo pathway effector Yap promotes cardiac regeneration. Proc Natl Acad Sci USA. (2013) 110:13839-44. doi: 10.1073/pnas.1313192110

93. von Gise A, Lin Z, Schlegelmilch K, Honor LB, Pan GM, Buck JN, et al. YAP1, the nuclear target of Hippo signaling, stimulates heart growth through cardiomyocyte proliferation but not hypertrophy. Proc Natl Acad Sci USA. (2012) 109:2394-9. doi: 10.1073/pnas.1116136109

94. Reginensi A, Scott RP, Gregorieff A, Bagherie-Lachidan M, Chung C, Lim $\mathrm{D}$-S, et al. Yap- and Cdc42-dependent nephrogenesis and morphogenesis during mouse kidney development. PLoS Genet. (2013) 9:e1003380. doi: 10.1371/journal.pgen.1003380

95. Schlegelmilch K, Mohseni M, Kirak O, Pruszak J, Rodriguez JR, Zhou D, et al. Yap1 acts downstream of $\alpha$-catenin to control epidermal proliferation. Cell (2011) 144:782-95. doi: 10.1016/j.cell.2011.02.031

96. Cai J, Zhang N, Zheng Y, de Wilde RF, Maitra A, Pan D. The Hippo signaling pathway restricts the oncogenic potential of an intestinal regeneration program. Genes Dev. (2010) 24:2383-8. doi: 10.1101/gad.1978810

97. Zhou D, Zhang Y, Wu H, Barry E, Yin Y, Lawrence E, et al. Mst1 and Mst2 protein kinases restrain intestinal stem cell proliferation and colonic tumorigenesis by inhibition of Yes-associated protein (Yap) overabundance. Proc Natl Acad Sci USA. (2011) 108:E1312-20. doi: 10.1073/pnas.11104 28108

98. Chen Q, Zhang N, Gray RS, Li H, Ewald AJ, Zahnow CA, et al. A temporal requirement for Hippo signaling in mammary gland differentiation, growth, and tumorigenesis. Genes Dev. (2014) 28:432-7. doi: 10.1101/gad.2336 76.113

99. Grijalva JL, Huizenga M, Mueller K, Rodriguez S, Brazzo J, Camargo F, et al. Dynamic alterations in Hippo signaling pathway and YAP activation during liver regeneration. Am J Physiol Gastrointest Liver Physiol. (2014) 307:G196-204. doi: 10.1152/ajpgi.00077.2014 
100. Su T, Bondar T, Zhou X, Zhang C, He H, Medzhitov R. Two-signal requirement for growth-promoting function of Yap in hepatocytes. Elife (2015) 4:e02948. doi: 10.7554/eLife.02948

101. Tanas MR, Sboner A, Oliveira AM, Erickson-Johnson MR, Hespelt J, Hanwright PJ, et al. Identification of a Disease-defining gene fusion in epithelioid hemangioendothelioma. Sci Transl Med. (2011) 3:98ra82. doi: 10.1126/scitranslmed.3002409

102. Heallen T, Morikawa Y, Leach J, Tao G, Willerson JT, Johnson RL, et al. Hippo signaling impedes adult heart regeneration. Development (2013) 140:468390. doi: 10.1242/dev.102798

103. Cao X, Pfaff SL, Gage FH. YAP regulates neural progenitor cell number via the TEA domain transcription factor. Genes Dev. (2008) 22:3320-34. doi: $10.1101 / \mathrm{gad} .1726608$

104. Lee K-P, Lee J-H, Kim T-S, Kim T-H, Park H-D, Byun J-S, et al. The Hippo-Salvador pathway restrains hepatic oval cell proliferation, liver size, and liver tumorigenesis. Proc Natl Acad Sci USA. (2010) 107:8248-53. doi: 10.1073/pnas.0912203107

105. Barry ER, Morikawa T, Butler BL, Shrestha K, de la Rosa R, Yan KS, et al. Restriction of intestinal stem cell expansion and the regenerative response by YAP. Nature (2013) 493:106-10. doi: 10.1038/nature11693

106. McKey J, Martire D, de Santa Barbara P, Faure S. LIX1 regulates YAP1 activity and controls the proliferation and differentiation of stomach mesenchymal progenitors. BMC Biol. (2016) 14:34. doi: 10.1186/s12915-016-0257-2

107. Zhang H, Pasolli HA, Fuchs E. Yes-associated protein (YAP) transcriptional coactivator functions in balancing growth and differentiation in skin. Proc Natl Acad Sci USA. (2011) 108:2270-5. doi: 10.1073/pnas.1019603108

108. He S, Nakada D, Morrison SJ. Mechanisms of stem cell self-renewal. Annu Rev Cell Dev Biol. (2009) 25:377-406. doi: 10.1146/annurev.cellbio.042308.113248

109. Thomson JA, Itskovitz-Eldor J, Shapiro SS, Waknitz MA, Swiergiel JJ, Marshall, Vivienne S, et al. Embryonic stem cell lines derived from human blastocysts. Science (1998) 282:1145-7. doi: 10.1126/science.282.5391.1145

110. Cockburn K, Rossant J. Making the blastocyst: lessons from the mouse. J Clin Invest. (2010) 120:995-1003. doi: 10.1172/JCI41229

111. Nishioka N, Inoue K-i, Adachi K, Kiyonari H, Ota M, Ralston A, et al. The Hippo signaling pathway components Lats and Yap pattern Tead4 activity to distinguish mouse trophectoderm from inner cell mass. Dev Cell (2009) 16:398-410. doi: 10.1016/j.devcel.2009.02.003

112. Home P, Saha B, Ray S, Dutta D, Gunewardena S, Yoo B, et al. Altered subcellular localization of transcription factor TEAD4 regulates first mammalian cell lineage commitment. Proc Natl Acad Sci USA. (2012) 109:7362-7. doi: 10.1073/pnas.1201595109

113. Makita R, Uchijima Y, Nishiyama K, Amano T, Chen Q, Takeuchi T, et al. Multiple renal cysts, urinary concentration defects, and pulmonary emphysematous changes in mice lacking TAZ. Am J Physiol Renal Physiol. (2008) 294:F542-53. doi: 10.1152/ajprenal.00201.2007

114. Tian Y, Kolb R, Hong J-H, Carroll J, Li D, You J, et al. TAZ promotes PC2 degradation through a SCFbeta-Trcp E3 ligase complex. Mol Cell Biol. (2007) 27:6383-95. doi: 10.1128/MCB.00254-07

115. Tamm C, Bower N, Anneren C. Regulation of mouse embryonic stem cell self-renewal by a Yes-YAP-TEAD2 signaling pathway downstream of LIF. J Cell Sci. (2011) 124:1136-44. doi: 10.1242/jcs.075796

116. Zhang H, Liu C-Y, Zha Z-Y, Zhao B, Yao J, Zhao S, et al. TEAD transcription factors mediate the function of TAZ in cell growth and epithelial-mesenchymal transition. J Biol Chem. (2009) 284:13355-62. doi: 10.1074/jbc.M900843200

117. Karpowicz P, Perez J, Perrimon N. The Hippo tumor suppressor pathway regulates intestinal stem cell regeneration. Development (2010) 137:4135-45. doi: 10.1242/dev.060483

118. Cockburn K, Biechele S, Garner J, Rossant J. The Hippo pathway member Nf2 is required for inner cell mass specification. Curr Biol. (2013) 23:1195201. doi: 10.1016/j.cub.2013.05.044

119. Hirate Y, Hirahara S, Inoue K-I, Suzuki A, Alarcon VB, Akimoto $\mathrm{K}$, et al. Polarity-dependent distribution of angiomotin localizes Hippo signaling in preimplantation embryos. Curr Biol. (2013) 23:1181-94. doi: 10.1016/j.cub.2013.05.014

120. Lorthongpanich C, Messerschmidt DM, Chan SW, Hong W, Knowles BB, Solter D. Temporal reduction of LATS kinases in the early preimplantation embryo prevents ICM lineage differentiation. Genes Dev. (2013) 27:1441-6. doi: $10.1101 / \operatorname{gad} .219618 .113$

121. Nishioka N, Yamamoto S, Kiyonari H, Sato H, Sawada A, Ota M, et al. Tead4 is required for specification of trophectoderm in pre-implantation mouse embryos. Mech Dev. (2008) 125:270-83. doi: 10.1016/j.mod.2007.11.002

122. Hossain Z, Ali SM, Ko HL, Xu J, Ng CP, Guo K, et al. Glomerulocystic kidney disease in mice with a targeted inactivation of Wwtr1. Proc Natl Acad Sci USA. (2007) 104:1631-6. doi: 10.1073/pnas.0605266104

123. Beyer TA, Weiss A, Khomchuk Y, Huang K, Ogunjimi AA, Varelas X, et al. Switch enhancers interpret TGF-beta and Hippo signaling to control cell fate in human embryonic stem cells. Cell Rep. (2013) 5:1611-24. doi: 10.1016/j.celrep.2013.11.021

124. Lian I, Kim J, Okazawa H, Zhao J, Zhao B, Yu J, et al. The role of YAP transcription coactivator in regulating stem cell self-renewal and differentiation. Genes Dev. (2010) 24:1106-18. doi: 10.1101/gad.1903310

125. Varelas X, Sakuma R, Samavarchi-Tehrani P, Peerani R, Rao BM, Dembowy $\mathrm{J}$, et al. TAZ controls Smad nucleocytoplasmic shuttling and regulates human embryonic stem-cell self-renewal. Nat Cell Biol. (2008) 10:837-48. doi: $10.1038 /$ ncb1748

126. Li P, Chen Y, Mak KK, Wong CK, Wang CC, Yuan P. Functional role of Mst1/Mst2 in embryonic stem cell differentiation. PLoS ONE (2013) 8:e79867. doi: 10.1371/journal.pone.0079867

127. Young RA. Control of the embryonic stem cell state. Cell (2011) 144:940-54 doi: 10.1016/j.cell.2011.01.032

128. Beyer TA, Narimatsu M, Weiss A, David L, Wrana JL. The TGF $\beta$ superfamily in stem cell biology and early mammalian embryonic development. Biochim Biophys Acta (2013) 1830:2268-79. doi: 10.1016/j.bbagen.2012.08.025

129. Weiss A, Attisano L. The TGFbeta superfamily signaling pathway. Wiley Interdiscip Rev Dev Biol. (2013) 2:47-63. doi: 10.1002/wdev.86

130. Varelas X, Samavarchi-Tehrani P, Narimatsu M, Weiss A, Cockburn K, Larsen BG, et al. The Crumbs complex couples cell density sensing to Hippodependent control of the TGF- $\beta$-SMAD pathway. Dev Cell (2010) 19:831-44. doi: 10.1016/j.devcel.2010.11.012

131. Chung H, Lee B-K, Uprety N, Shen W, Lee J, Kim J. Yap1 is dispensable for self-renewal but required for proper differentiation of mouse embryonic stem (ES) cells. EMBO Rep. (2016) 17:519-29. doi: 10.15252/embr.201540933

132. Aylon Y, Sarver A, Tovy A, Ainbinder E, Oren M. Lats2 is critical for the pluripotency and proper differentiation of stem cells. Cell Death Differ. (2014) 21:624-33. doi: 10.1038/cdd.2013.188

133. Takahashi K, Yamanaka S. Induction of pluripotent stem cells from mouse embryonic and adult fibroblast cultures by defined factors. Cell (2006) 126:663-76. doi: 10.1016/j.cell.2006.07.024

134. Qin H, Blaschke K, Wei G, Ohi Y, Blouin L, Qi Z, et al. Transcriptional analysis of pluripotency reveals the Hippo pathway as a barrier to reprogramming. Hum Mol Genet. (2012) 21:2054-67. doi: $10.1093 / \mathrm{hmg} / \mathrm{dds} 023$

135. Zhao Y, Fei X, Guo J, Zou G, Pan W, Zhang J, et al. Induction of reprogramming of human amniotic epithelial cells into iPS cells by overexpression of Yap, Oct4, and Sox2 through the activation of the HippoYap pathway. Exp Ther Med. (2017) 14:199-206. doi: 10.3892/etm.2017.4512

136. Qin H, Hejna M, Liu Y, Percharde M, Wossidlo M, Blouin L, et al. YAP Induces Human Naive Pluripotency. Cell Rep. (2016) 14:2301-12. doi: 10.1016/j.celrep.2016.02.036

137. Benhamouche S, Curto M, Saotome I, Gladden AB, Liu C-H, Giovannini M, et al. Nf2/Merlin controls progenitor homeostasis and tumorigenesis in the liver. Genes Dev. (2010) 24:1718-30. doi: 10.1101/gad.1938710

138. Liu-Chittenden Y, Huang B, Shim JS, Chen Q, Lee S-J, Anders RA, et al. Genetic and pharmacological disruption of the TEAD-YAP complex suppresses the oncogenic activity of YAP. Genes Dev. (2012) 26:1300-5. doi: $10.1101 /$ gad.192856.112

139. Moroishi T, Hansen CG, Guan K-L. The emerging roles of YAP and TAZ in cancer. Nat Rev Cancer (2015) 15:73-9. doi: 10.1038/nrc3876

140. Steinhardt AA, Gayyed MF, Klein AP, Dong J, Maitra A, Pan D, et al. Expression of Yes-associated protein in common solid tumors. Hum Pathol. (2008) 39:1582-9. doi: 10.1016/j.humpath.2008. 04.012

141. Fernandez BG, Gaspar P, Bras-Pereira C, Jezowska B, Rebelo SR, Janody F. Actin-Capping Protein and the Hippo pathway regulate F-actin and tissue 
growth in Drosophila. Development (2011) 138:2337-46. doi: 10.1242/dev.0 63545

142. Sekido Y. Inactivation of Merlin in malignant mesothelioma cells and the Hippo signaling cascade dysregulation. Pathol Int. (2011) 61:331-44. doi: 10.1111/j.1440-1827.2011.02666.x

143. Errani C, Zhang L, Sung YS, Hajdu M, Singer S, Maki RG, et al. A novel WWTR1-CAMTA1 gene fusion is a consistent abnormality in epithelioid hemangioendothelioma of different anatomic sites. Genes Chromosomes Cancer (2011) 50:644-53. doi: 10.1002/gcc.20886

144. Flucke U, Vogels RJ, de Saint Aubain Somerhausen N, Creytens DH, Riedl RG, van Gorp JM, et al. Epithelioid Hemangioendothelioma: clinicopathologic, immunhistochemical, and molecular genetic analysis of 39 cases. Diagn Pathol. (2014) 9:131. doi: 10.1186/1746-1596-9-131

145. Pajtler KW, Witt H, Sill M, Jones DTW, Hovestadt V, Kratochwil F, et al. Molecular classification of ependymal tumors across all CNS compartments, histopathological grades, and age groups. Cancer Cell (2015) 27:728-43. doi: 10.1016/j.ccell.2015.04.002

146. Antonescu CR, Le Loarer F, Mosquera JM, Sboner A, Zhang L, Chen $\mathrm{CL}$, et al. Novel YAP1-TFE3 fusion defines a distinct subset of epithelioid hemangioendothelioma. Genes Chromosomes Cancer (2013) 52:775-84. doi: $10.1002 /$ gcc. 22073

147. Li S, Shen D, Shao J, Crowder R, Liu W, Prat A, et al. Endocrinetherapy-resistant ESR1 variants revealed by genomic characterization of breast-cancer-derived xenografts. Cell Rep. (2013) 4:1116-30. doi: 10.1016/j.celrep.2013.08.022

148. Parker M, Mohankumar KM, Punchihewa C, Weinlich R, Dalton JD, Li $\mathrm{Y}$, et al. C11orf95-RELA fusions drive oncogenic NF-kappaB signalling in ependymoma. Nature (2014) 506:451-5. doi: 10.1038/nature13109

149. Chen H-Y, Yu S-L, Ho B-C, Su K-Y, Hsu Y-C, Chang C-S, et al. R331W Missense mutation of oncogene YAP1 is a germline risk allele for lung adenocarcinoma with medical actionability. J Clin Oncol. (2015) 33:2303-10. doi: 10.1200/JCO.2014.59.3590

150. Fernandez LA, Northcott PA, Dalton J, Fraga C, Ellison D, Angers $\mathrm{S}$, et al. YAP1 is amplified and up-regulated in hedgehog-associated medulloblastomas and mediates Sonic hedgehog-driven neural precursor proliferation. Genes Dev. (2009) 23:2729-41. doi: 10.1101/gad.1824509

151. Yu T, Bachman J, Lai ZC. Evidence for a tumor suppressor role for the large tumor suppressor genes LATS1 and LATS2 in human cancer. Genetics (2013) 195:1193-6. doi: 10.1534/genetics.113.156372

152. Murakami H, Mizuno T, Taniguchi T, Fujii M, Ishiguro F, Fukui T, et al. LATS2 is a tumor suppressor gene of malignant mesothelioma. Cancer Res. (2011) 71:873-83. doi: 10.1158/0008-5472.CAN-10-2164

153. Song Y, Li L, Ou Y, Gao Z, Li E, Li X, et al. Identification of genomic alterations in oesophageal squamous cell cancer. Nature (2014) 509:91-5. doi: 10.1038/nature13176

154. Miyanaga A, Masuda M, Tsuta K, Kawasaki K, Nakamura Y, Sakuma T, et al. Hippo pathway gene mutations in malignant mesothelioma: revealed by RNA and targeted exon sequencing. J Thorac Oncol. (2015) 10:844-51. doi: 10.1097/JTO.0000000000000493

155. Cottini F, Hideshima T, Xu C, Sattler M, Dori M, Agnelli L, et al. Rescue of Hippo coactivator YAP1 triggers DNA damage-induced apoptosis in hematological cancers. Nat Med. (2014) 20:599-606. doi: 10.1038/nm.3562

156. Gao Y, Zhang W, Han X, Li F, Wang X, Wang R, et al. YAP inhibits squamous transdifferentiation of Lkb1-deficient lung adenocarcinoma through ZEB2-dependent DNp63 repression. Nat Commun. (2014) 5:4629. doi: $10.1038 /$ ncomms5629

157. Mohseni M, Sun J, Lau A, Curtis S, Goldsmith J, Fox VL, et al. A genetic screen identifies an LKB1-MARK signalling axis controlling the Hippo-YAP pathway. Nat Cell Biol. (2014) 16:108-17. doi: 10.1038/ ncb2884

158. Zhang W, Nandakumar N, Shi Y, Manzano M, Smith A, Graham G, et al. Downstream of mutant KRAS, the transcription regulator YAP is essential for neoplastic progression to pancreatic ductal adenocarcinoma. Sci Signal. (2014) 7:ra42. doi: 10.1126/scisignal.2005049

159. Zhao B, Li L, Wang L, Wang C-Y, Yu J, Guan K-L. Cell detachment activates the Hippo pathway via cytoskeleton reorganization to induce anoikis. Genes Dev. (2012) 26:54-68. doi: 10.1101/gad.173435.111
160. Chen D, Sun Y, Wei Y, Zhang P, Rezaeian AH, Teruya-Feldstein J, et al. LIFR is a breast cancer metastasis suppressor upstream of the Hippo-YAP pathway and a prognostic marker. Nat Med. (2012) 18:1511-7. doi: 10.1038/nm.2940

161. Cordenonsi M, Zanconato F, Azzolin L, Forcato M, Rosato A, Frasson C, et al. The Hippo transducer TAZ confers cancer stem cell-related traits on breast cancer cells. Cell (2011) 147:759-72. doi: 10.1016/j.cell.2011.09.048

162. Nallet-Staub F, Marsaud V, Li L, Gilbert C, Dodier S, Bataille V, et al. Proinvasive activity of the Hippo pathway effectors YAP and TAZ in cutaneous melanoma. J Invest Dermatol. (2014) 134:123-32. doi: 10.1038/jid.2013.319

163. Diepenbruck M, Waldmeier L, Ivanek R, Berninger P, Arnold P, van Nimwegen E, et al. Tead2 expression levels control the subcellular distribution of Yap and Taz, zyxin expression and epithelial-mesenchymal transition. J Cell Sci. (2014) 127:1523-36. doi: 10.1242/jcs.139865

164. Hsu YL, Hung JY, Chou SH, Huang MS, Tsai MJ, Lin YS, et al. Angiomotin decreases lung cancer progression by sequestering oncogenic YAP/TAZ and decreasing Cyr61 expression. Oncogene (2015) 34:4056-68. doi: 10.1038/onc.2014.333

165. Lau AN, Curtis SJ, Fillmore CM, Rowbotham SP, Mohseni M, Wagner $\mathrm{DE}$, et al. Tumor-propagating cells and Yap/Taz activity contribute to lung tumor progression and metastasis. EMBO J. (2014) 33:468-81. doi: $10.1002 / \mathrm{embj} .201386082$

166. Gu JJ, Rouse C, Xu X, Wang J, Onaitis MW, Pendergast AM. Inactivation of ABL kinases suppresses non-small cell lung cancer metastasis. JCI Insight (2016) 1:e89647. doi: 10.1172/jci.insight.89647

167. Liu J, Ye L, Li Q, Wu X, Wang B, Ouyang Y, et al. Synaptopodin-2 suppresses metastasis of triple-negative breast cancer via inhibition of YAP/TAZ activity. J Pathol. (2018) 244:71-83. doi: 10.1002/path.4995

168. Li C, Wang S, Xing Z, Lin A, Liang K, Song J, et al. A ROR1-HER3lncRNA signalling axis modulates the Hippo-YAP pathway to regulate bone metastasis. Nat Cell Biol. (2017) 19:106-19. doi: 10.1038/ncb3464

169. Wang T, Mao B, Cheng C, Zou Z, Gao J, Yang Y, et al. YAP promotes breast cancer metastasis by repressing growth differentiation factor-15. Biochim Biophys Acta (2018) 1864:1744-53. doi: 10.1016/j.bbadis.2018.02.020

170. Han S, Wang D, Tang G, Yang X, Jiao C, Yang R, et al. Suppression of miR-16 promotes tumor growth and metastasis through reversely regulating YAP1 in human cholangiocarcinoma. Oncotarget (2017) 8:5663550. doi: 10.18632/oncotarget.17832

171. Qiao Y, Chen J, Lim YB, Finch-Edmondson ML, Seshachalam VP, Qin L, et al. YAP Regulates actin dynamics through ARHGAP29 and promotes metastasis. Cell Rep. (2017) 19:1495-502. doi: 10.1016/j.celrep.2017.04.075

172. Yin K, Dang S, Cui L, Fan X, Wang L, Xie R, et al. Netrin-1 promotes metastasis of gastric cancer by regulating YAP activity. Biochem Biophys Res Commun. (2018) 496:76-82. doi: 10.1016/j.bbrc.2017.12.170

173. Haemmerle M, Taylor ML, Gutschner T, Pradeep S, Cho MS, Sheng J, et al. Platelets reduce anoikis and promote metastasis by activating YAP1 signaling. Nat Commun. (2017) 8:310. doi: 10.1038/s41467-017-00411-z

174. Mu L, Huang K, Hu Y, Yan C, Li X, Tao D, et al. Small-sized colorectal cancer cells harbor metastatic tumor-initiating cells. Oncotarget (2017) 8:10790719. doi: 10.18632 /oncotarget.22392

175. Liu Y, Wang G, Yang Y, Mei Z, Liang Z, Cui A, et al. Increased TEAD4 expression and nuclear localization in colorectal cancer promote epithelialmesenchymal transition and metastasis in a YAP-independent manner. Oncogene (2016) 35:2789-800. doi: 10.1038/onc.2015.342

176. Yang S, Zhang L, Purohit V, Shukla S, Chen X, Yu F, et al. Active YAP promotes pancreatic cancer cell motility, invasion and tumorigenesis in a mitotic phosphorylation-dependent manner through LPAR3. Oncotarget (2015) 6:36019-31. doi: 10.18632/oncotarget.5935

177. Bartucci M, Dattilo R, Moriconi C, Pagliuca A, Mottolese M, Federici G, et al. TAZ is required for metastatic activity and chemoresistance of breast cancer stem cells. Oncogene (2015) 34:681-90. doi: 10.1038/onc.2014.5

178. Zhou P-J, Xue W, Peng J, Wang Y, Wei L, Yang Z, et al. Elevated expression of Par3 promotes prostate cancer metastasis by forming a Par3/aPKC/KIBRA complex and inactivating the hippo pathway. J Exp Clin Cancer Res. (2017) 36:139. doi: 10.1186/s13046-017-0609-y

179. Matteucci E, Maroni P, Luzzati A, Perrucchini G, Bendinelli P, Desiderio MA. Bone metastatic process of breast cancer involves methylation state affecting E-cadherin expression through TAZ and WWOX nuclear effectors. Eur J Cancer (2013) 49:231-44. doi: 10.1016/j.ejca.2012.05.006 
180. Janse van Rensburg HJ, Azad T, Ling M, Hao Y, Snetsinger B, Khanal P, et al. The Hippo Pathway Component TAZ Promotes Immune Evasion in Human Cancer through PD-L1. Cancer Res. (2018) 78:1457-70. doi: 10.1158/0008-5472.CAN-17-3139

181. Rauch J, Kolch W. Spatial regulation of ARAF controls the MST2-Hippo pathway. Small GTPases (2017) 10:1-6. doi: 10.1080/21541248.2017.1288686

182. Lai D, Ho KC, Hao Y, Yang X. Taxol resistance in breast cancer cells is mediated by the hippo pathway component TAZ and its downstream transcriptional targets Cyr61 and CTGF. Cancer Res. (2011) 71:2728-38. doi: 10.1158/0008-5472.CAN-10-2711

183. Touil Y, Igoudjil W, Corvaisier M, Dessein A-F, Vandomme J, Monte D, et al. Colon cancer cells escape 5FU chemotherapy-induced cell death by entering stemness and quiescence associated with the c-Yes/YAP axis. Clin Cancer Res. (2014) 20:837-46. doi: 10.1158/1078-0432.CCR-13-1854

184. Lin L, Sabnis AJ, Chan E, Olivas V, Cade L, Pazarentzos E, et al. The Hippo effector YAP promotes resistance to RAF- and MEK-targeted cancer therapies. Nat Genet. (2015) 47:250-6. doi: 10.1038/ng.3218

185. Kapoor A, Yao W, Ying H, Hua S, Liewen A, Wang Q, et al. Yapl activation enables bypass of oncogenic Kras addiction in pancreatic cancer. Cell (2014) 158:185-97. doi: 10.1016/j.cell.2014.06.003

186. Zhou X, Wang S, Wang Z, Feng X, Liu P, Lv XB, et al. Estrogen regulates Hippo signaling via GPER in breast cancer. J Clin Invest. (2015) 125:2123-35. doi: $10.1172 /$ JCI79573

187. Shao DD, Xue W, Krall EB, Bhutkar A, Piccioni F, Wang X, et al. KRAS and YAP1 converge to regulate EMT and tumor survival. Cell (2014) 158:171-84. doi: 10.1016/j.cell.2014.06.004

188. Kim T, Yang S-J, Hwang D, Song J, Kim M, Kyum Kim S, et al. A basal-like breast cancer-specific role for SRF-IL6 in YAP-induced cancer stemness. Nat Commun. (2015) 6:10186. doi: 10.1038/ncomms10186

189. Guo Y, Cui J, Ji Z, Cheng C, Zhang K, Zhang C, et al. miR302/367/LATS2/YAP pathway is essential for prostate tumor-propagating cells and promotes the development of castration resistance. Oncogene (2017) 36:6336-47. doi: 10.1038/onc.2017.240

190. Song S, Ajani JA, Honjo S, Maru DM, Chen Q, Scott AW, et al. Hippo coactivator YAP1 upregulates SOX9 and endows esophageal cancer cells with stem-like properties. Cancer Res. (2014) 74:4170-82. doi: 10.1158/0008-5472.CAN-13-3569

191. Chan SW, Lim CJ, Guo K, Ng CP, Lee I, Hunziker W, et al. A role for TAZ in migration, invasion, and tumorigenesis of breast cancer cells. Cancer Res. (2008) 68:2592-8. doi: 10.1158/0008-5472.CAN-07-2696

192. Basu-Roy U, Bayin NS, Rattanakorn K, Han E, Placantonakis DG, Mansukhani A, et al. Sox2 antagonizes the Hippo pathway to maintain stemness in cancer cells. Nat Commun. (2015) 6:6411. doi: $10.1038 /$ ncomms7411

193. Ooki A, Del Carmen Rodriguez Pena M, Marchionni L, Dinalankara W, Begum A, Hahn NM, et al. YAP1 and COX2 Coordinately Regulate Urothelial Cancer Stem-like Cells. Cancer Res. (2018) 78:168-81. doi: 10.1158/0008-5472.CAN-17-0836

194. Wang C, Gu C, Jeong KJ, Zhang D, Guo W, Lu Y, et al. YAP/TAZ-Mediated Upregulation of GAB2 Leads to Increased Sensitivity to Growth FactorInduced Activation of the PI3K Pathway. Cancer Res. (2017) 77:1637-48. doi: 10.1158/0008-5472.CAN-15-3084

195. Song S, Honjo S, Jin J, Chang S-S, Scott AW, Chen Q, et al. The Hippo Coactivator YAP1 Mediates EGFR overexpression and confers chemoresistance in esophageal cancer. Clin Cancer Res. (2015) 21:2580-90. doi: 10.1158/1078-0432.CCR-14-2191

196. Zhang W-Q, Dai Y-Y, Hsu P-C, Wang H, Cheng L, Yang Y-L, et al. Targeting YAP in malignant pleural mesothelioma. J Cell Mol Med. (2017) 21:2663-76. doi: $10.1111 /$ jcmm. 13182

197. Zhang H, Ramakrishnan SK, Triner D, Centofanti B, Maitra D, Gyorffy $\mathrm{B}$, et al. Tumor-selective proteotoxicity of verteporfin inhibits colon cancer progression independently of YAP1. Sci Signal. (2015) 8:ra98. doi: $10.1126 /$ scisignal.aac5418

198. Gibault F, Corvaisier M, Bailly F, Huet G, Melnyk P, Cotelle P. Nonphotoinduced biological properties of verteporfin. Curr Med Chem. (2016) 23:1171-84. doi: 10.2174/0929867323666160316125048

199. Konstantinou EK, Notomi S, Kosmidou C, Brodowska K, Al-Moujahed A, Nicolaou F, et al. Verteporfin-induced formation of protein cross-linked oligomers and high molecular weight complexes is mediated by light and leads to cell toxicity. Sci Rep. (2017) 7:46581. doi: 10.1038/srep46581

200. Zanconato F, Battilana G, Cordenonsi M, Piccolo S. YAP/TAZ as therapeutic targets in cancer. Curr Opin Pharmacol. (2016) 29:26-33. doi: 10.1016/j.coph.2016.05.002

201. Gibault F, Sturbaut M, Bailly F, Melnyk P, Cotelle P. Targeting Transcriptional Enhanced Associate Domains (TEADs). J Med Chem. (2018) 61:5057-72. doi: 10.1021/acs.jmedchem.7b00879

202. Zhao Y, Yang X. The Hippo pathway in chemotherapeutic drug resistance. Int J Cancer (2015) 137:2767-73. doi: 10.1002/ijc.29293

203. Fan F, He Z, Kong L-L, Chen Q, Yuan Q, Zhang S, et al. Pharmacological targeting of kinases MST1 and MST2 augments tissue repair and regeneration. Sci Transl Med. (2016) 8:352ra108. doi: $10.1126 /$ scitranslmed.aaf 2304

204. Ruiz MM, Regueiro JR. New tools in regenerative medicine: gene therapy. Adv Exp Med Biol. (2012) 741:254-75. doi: 10.1007/978-1-4614-2098-9_17

205. Yin H, Kanasty RL, Eltoukhy AA, Vegas AJ, Dorkin JR, Anderson DG. Non-viral vectors for gene-based therapy. Nat Rev Genet. (2014) 15:541-55. doi: $10.1038 / \operatorname{nrg} 3763$

206. Clevers H. Modeling development and disease with Organoids. Cell (2016) 165:1586-97. doi: 10.1016/j.cell.2016.05.082

207. Yin X, Mead BE, Safaee H, Langer R, Karp JM, Levy O. Engineering stem cell organoids. Cell Stem Cell (2016) 18:25-38. doi: 10.1016/j.stem.2015.12.005

208. Panciera T, Azzolin L, Fujimura A, Di Biagio D, Frasson C, Bresolin $\mathrm{S}$, et al. Induction of expandable tissue-specific stem/progenitor cells through transient expression of YAP/TAZ. Cell Stem Cell (2016) 19:725-37. doi: 10.1016/j.stem.2016.08.009

209. Gong R, Yu F-X. Targeting the hippo pathway for anti-cancer therapies. Curr Med Chem. (2015) 22:4104-17. doi: 10.2174/0929867322666151002112256

210. Huang SS, Chang NS. Phosphorylation/de-phosphorylation in specific sites of tumor suppressor WWOX and control of distinct biological events. Exp Biol Med. (2018) 243:137-47. doi: 10.1177/15353702177 52350

211. Liu CC, Ho PC, Lee IT, Chen YA, Chu CH, Teng CC, et al. WWOX phosphorylation, signaling, and role in neurodegeneration. Front Neurosci. (2018) 12:563. doi: 10.3389/fnins.2018.00563

212. Callus BA, Finch-Edmondson ML, Fletcher S, Wilton SD. YAPping about and not forgetting TAZ. FEBS Lett. (2018). doi: 10.1002/1873-3468.13318. [Epub ahead of print].

213. Qin Z, Xia W, Fisher GJ, Voorhees JJ, Quan T. YAP/TAZ regulates TGF$\beta /$ Smad3 signaling by induction of Smad7 via AP1 in human skin dermal fibroblasts. Cell Commun Signal. (2018) 16:18. doi: 10.1186/s12964-018-0232-3

214. Ben Mimoun S, Mauviel A. Molecular mechanisms underlying TGFß/Hippo signaling crosstalks - Role of baso-apical epithelial cell polarity. Int J Biochem Cell Biol. (2018) 98:75-81. doi: 10.1016/j.biocel.2018.03.006.

215. Zhang K, Qi HX, Hu ZM, Chang YN, Shi ZM, Han XH, et al. YAP and TAZ Take center stage in cancer. Biochemistry (2015) 54:6555-66. doi: 10.1021/acs.biochem.5b01014

216. Piersma B, Bank RA, Boersema M. Signaling in Fibrosis: TGF $\beta$, WNT, and YAP/TAZ Converge. Front Med. (2015) 2:59. doi: 10.3389/fmed.2015.00059

217. Bouteille N, Driouch K, Hage PE, Sin S, Formstecher E, Camonis $\mathrm{J}$, et al. Inhibition of the Wnt/beta-catenin pathway by the WWOX tumor suppressor protein. Oncogenet (2009) 28:2569-80. doi: 10.1038/onc.2009.120.

218. Hsu LJ, Chiang MF, Sze CI, Su WP, Yap YV, Lee IT, Kuo HL, Chang NS. HYAL-2-WWOX-SMAD4 signaling in cell death and anticancer response. Front Cell Dev Biol. (2016) 4:141. doi: 10.3389/fcell.2016.00141

219. Hsu LJ, Hong Q, Chen ST, Kuo HL, Schultz L, Heath J, et al. Hyaluronan activates Hyal-2/WWOX/Smad4 signaling and causes bubbling cell death when the signaling complex is overexpressed. Oncotarget (2017) 8:19137-55. doi: 10.18632/oncotarget. 13268

220. Aldaz CM, Ferguson BW, Abba MC. WWOX at the crossroads of cancer, metabolic syndrome related traits and CNS pathologies. Biochim Biophys Acta (2014) 1846:188-200. doi: 10.1016/j.bbcan.2014.06.001

221. Wang HY, Juo LI, Lin YT, Hsiao M, Lin JT, Tsai CH, et al. WW domaincontaining oxidoreductase promotes neuronal differentiation via negative 
regulation of glycogen synthase kinase 3 3 . Cell Death Differ. (2012) 19:104959. doi: $10.1038 / \mathrm{cdd} .2011 .188$

222. Holt R, Ceroni F, Bax DA, Broadgate S, Diaz DG, Santos C, et al. New variant and expression studies provide further insight into the genotype-phenotype correlation in YAP1related developmental eye disorders. Sci Rep. (2017) 7:7975. doi: 10.1038/s41598-017-08397-w

223. Farooq A. Structural insights into the functional versatility of WW domain-containing oxidoreductase tumor suppressor. Exp Biol Med. (2015) 240:361-74. doi: 10.1177/15353702145 61586
Conflict of Interest Statement: The authors declare that the research was conducted in the absence of any commercial or financial relationships that could be construed as a potential conflict of interest.

Copyright $\odot 2019$ Chen, Lu, Cheng, Pan, Chen and Chang. This is an open-access article distributed under the terms of the Creative Commons Attribution License (CC $B Y)$. The use, distribution or reproduction in other forums is permitted, provided the original author(s) and the copyright owner(s) are credited and that the original publication in this journal is cited, in accordance with accepted academic practice. No use, distribution or reproduction is permitted which does not comply with these terms. 